\title{
Amphibia of Enspel (Late Oligocene, Germany)
}

\author{
Zbyněk Roček • Michael Wuttke
}

Received: 23 April 2010 /Revised: 9 July 2010 / Accepted: 12 August 2010 /Published online: 29 September 2010

(C) Senckenberg Gesellschaft für Naturforschung and Springer 2010

\begin{abstract}
Amphibia from the Late Oligocene (MP 28) locality Enspel, Germany are represented by two caudates: a hyperossified salamandrid Chelotriton paradoxus and an indeterminate salamandrid different from Chelotriton in proportions of vertebral column. Anurans are represented by two forms of the genus Palaeobatrachus, one of which is nearly as large as $P$. gigas (now synonymized with $P$. grandipes). Pelobates cf. decheni, represented in this locality by three nearly complete adult skeletons and a large number of tadpoles, is the earliest record for the genus. Compared with later representatives of the genus, it does not yet possess specializations for burrowing. Ranidae are represented by two rather fragmentary and incomplete skeletons referred to as Rana sp. A comparatively large series of tadpoles was assigned to the Pelobatidae on the basis of tripartite frontoparietal complex. Most of them are premetamorphic larvae, and a few older ones are postmetamorphic, but they do not exceed Gossner stage 42 .
\end{abstract}

This article is an additional contribution to the special issue "Fossillagerstätte Enspel - exceptional preservation in an Upper Oligocene maar

\section{Z. Roček $(\bowtie)$}

Department of Palaeobiology, Institute of Geology,

Academy of Sciences of the Czech Republic,

Prague, Czech Republic

e-mail: Rocek@gli.cas.cz

\section{Z. Roček}

Department of Zoology, Charles University,

Prague, Czech Republic

\section{Wuttke}

Section Geological History of the Earth,

General Department of Cultural Heritage Rhineland Palatinate,

Mainz, Germany

e-mail: erdgeschichte@gdke.rlp.de
One specimen is a large premetamorphic tadpole (no rudimentary limbs) with a total body length of $147 \mathrm{~mm}$. Anatomically, it can be equally assigned to Pelobates or to Eopelobates; the second possibility was excluded only on the basis of absence of adult Eopelobates in this locality.

Keywords Enspel · Oligocene · Salamandridae · Chelotriton - Anura Palaeobatrachus $\cdot$ Pelobates $\cdot$ Rana

\section{Abbreviation \\ DP FNSP Department of Palaeontology Faculty of Natural Sciences, Prague}

\section{Introduction}

The locality Enspel represents a Late Oligocene crater lake (Maar) located about $35 \mathrm{~km}$ NE of Koblenz, Germany $\left(50^{\circ}\right.$ $36^{\prime} 50 \mathrm{~N}, 7^{\circ} 53^{\prime} 40 \mathrm{E}$ ), on the edge of the so-called Westerwald volcanic field (marked by broken line in Fig. 1). It contains laminated lacustrine deposits (black pelites) with, among others, fossil amphibians. These deposits were classified by Storch et al. (1996) into mammal zone MP 28, and Mertz et al. (2007) dated their age as 24.79-24.56 Ma. The lake was meromictic and eutrophic, had no outlet, and a mesophytic forest extended up to the lake margins (Wuttke and Poschmann 2010). The mean annual temperature was estimated as about $15-17^{\circ} \mathrm{C}$, the warmest month mean as about $25^{\circ} \mathrm{C}$, the coldest month mean as about $5-7^{\circ} \mathrm{C}$, and the mean annual precipitation was between 900 and 1,355 mm/year (Uhl and Herrmann 2010). The most abundant fossil vertebrates from the locality are anuran tadpoles (Maus and Wuttke 2002, 2004), which were found in the thousands (Wuttke and Poschmann 2010), but adult 


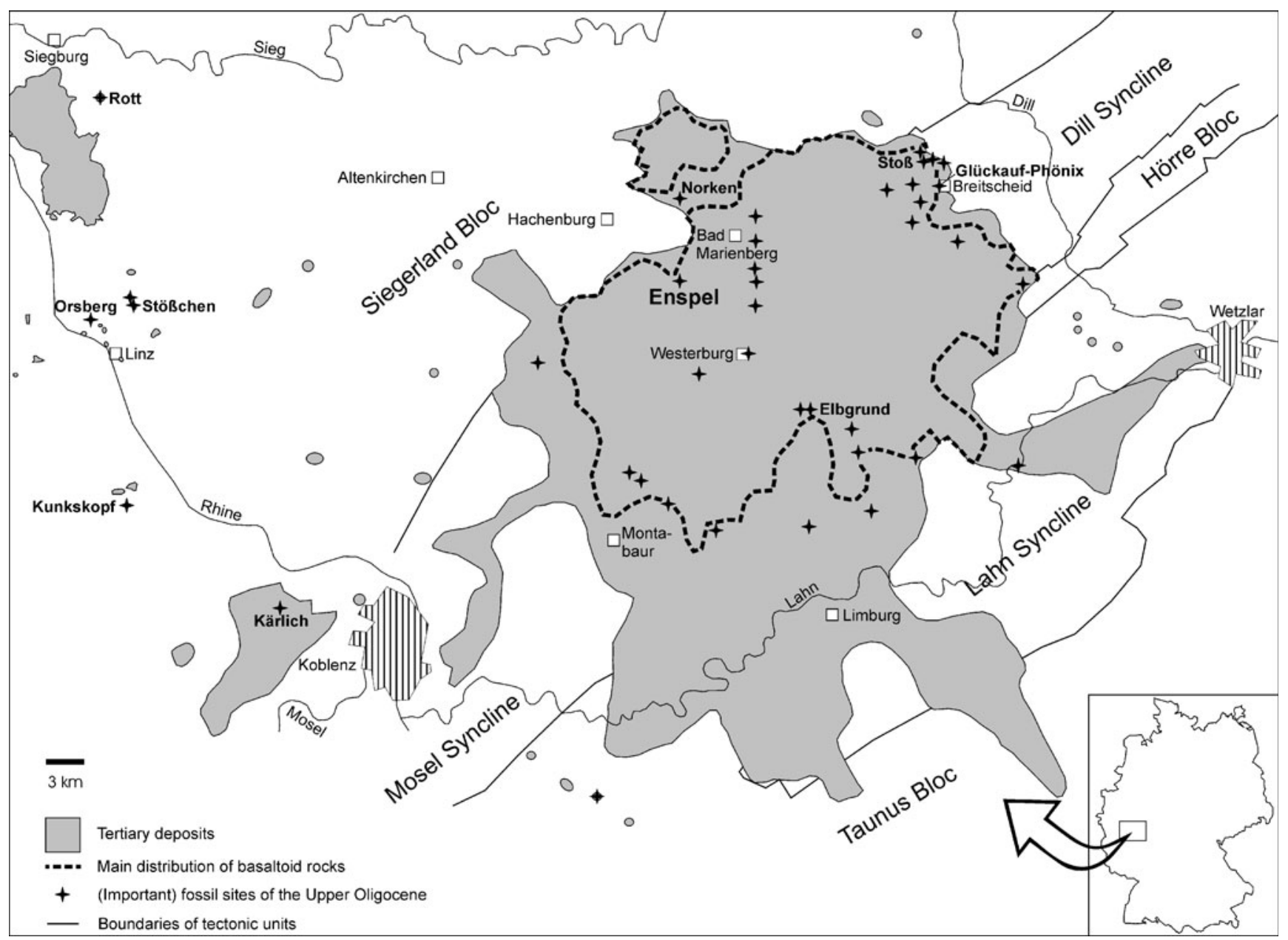

Fig. 1 Geological map of the Westerwald Tertiary; outlines of Tertiary deposits and of basaltoid rocks simplified (compiled after Ahrens 1960; Kromer 1980; Hessisches Landesamt für Bodenforschung 1989; Meyer and Stets 2000; Landesamt für Geologie und Bergbau 2003), from Schindler and Wuttke (2010)

noachicus and Chelotriton paradoxus in Rott near Bonn, Germany (Westphal 1958; Roček 1996a, b) in the Late Oligocene. Anurans decreased in their diversity.

The Late Oligocene is the period in which Recent genera such as Rana, Pelobates and probably Discoglossus emerged, and it preceded the Early Miocene when the European batrachofauna reached the maximum of its taxonomic diversification (Rage and Roček 2003). Therefore, any locality of this age is of high importance in terms of providing information both on the local biota as well as on the palaeoenvironment. As regards to the amphibians, there are three localities in central Europe that provide information of this kind: Rott near Bonn, Germany, which has been palaeontologically exploited since the 1830s (von Koenigswald et al. 1992), Bechlejovice in north Bohemia, Czech Republic (Špinar 1972), and Enspel, Germany. The aim of this paper is to give an account of the amphibian fauna from Enspel and compare it with other contemporary localities. 


\section{Materials and methods}

The material from Enspel locality was collected since 1990 by the staff of the Generaldirection Kulturelles Erbe RLP, Referat Erdgeschichte (General Department of Cultural Heritage Rhineland Palatinate, Section Geological History of the Earth) in Mainz (Felder et al. 1998) and is deposited in the collections of Landessammlung für Naturkunde RheinlandPfalz (Naturhistorisches Museum Mainz, NHMM).

Amphibians from Enspel are preserved as more or less articulated skeletons, sometimes including also nonbiomineralized soft tissues such as tail fins of anuran tadpoles (Toporski et al. 2002). Some specimens were first prepared from the side that was originally exposed when collected (e.g., Figs. 2a $\mathrm{a}_{1}, 2,5, \mathrm{~b}_{2,3}, 4 \mathrm{~h}$ and $7 \mathrm{a}-\mathrm{c}$ ). After investigation and graphic and photographic documentation the exposed fossil was embedded in epoxy resin and prepared from the opposite side (Figs. 2a $\mathrm{a}_{3}, \mathrm{~b}_{4}, 4 \mathrm{~g}$, i and 6d).

\section{Systematic palaeontology}

Order Caudata Scopoli, 1777

Family Salamandridae Goldfuss, 1820

Genus Chelotriton Pomel, 1853

\section{Chelotriton paradoxus Pomel, 1853}

Material: Three individuals in various complementary stages of preparation were available for this study. PW1995/5810-LS was preserved as part (Fig. 2a $a_{3}$ ) and counterpart (Fig. $2 \mathrm{a}_{4}$ ). The skeleton was exposed in ventral aspect on the part, and this was embedded in epoxy so that the dorsal side could be exposed through preparation (Fig. $2 \mathrm{a}_{1,2,5}$ ). PW1995/5809-LS was also exposed in ventral aspect (Fig. 2 $\mathrm{b}_{4}$ ) and later prepared to reveal the dorsal side (Fig. $2 b_{2}, 3$ ). Both specimens include skull and postcranial skeleton and are only moderately disarticulated. Specimen PW1995/5826-LS (Fig. 2c) consists of the presacral part of the vertebral column with ribs and some parts of the appendicular skeleton preserved in dorsal view. All three individuals allow complete reconstruction of the skeleton.

Description: The triangular skull is short and wide. In ventral aspect, the most conspicuous feature is the hyobranchial skeleton (Fig. $2 b_{4}$ ), which was well ossified. It consists of the anterior copula (= basihyal) situated in the midline, and two stout and moderately bent ceratohyals that join one another anteriorly. As evidenced by the specimen illustrated in Fig. $2 a_{3}$, their distal ends were articulated with the epihyal. Another, parallel epibranchial may be recognized on both sides of the skull in dorsal view (Fig. 2a $a_{2}$ ). A noteworthy fact illustrating how important is the degree of preservation in recognizing these elements is that only one of them was distinguishable when the ventral side of the specimen was exposed (Fig. 2a $a_{3}$ ). The middle part of the palate is occupied by the parasphenoid. As suggested by bone impressons on the specimen illustrated in Fig. $2 b_{4}$, the lateral margins of the palatines were rimmed with rows of teeth. The mandibles contact one another anteriorly to form the median symphysis, which was originally syndesmotic. The premaxillae are large, dentate and covered with dense pustular sculpture. The maxillae are dentate and the presence of a quadratojugal indicates that the maxillary arch was complete (Fig. $2 \mathrm{a}_{5}, \mathrm{~b}_{1}$ ). The posteromedial border of the orbits was formed by the fronto-squamosal bridge connecting the lateral part of the frontal with the squamosal. Both otic capsules are only moderately prominent, so the posterior outline of the skull is nearly transverse.

The presacral vertebral column consists of 13 opisthocoelous vertebrae (Fig. 2c), the spinal processess of which are terminated by horizontal dilatations covered with pustular sculpture at their tops. These dorsal sculptured dilatations articulate with one another so that the convex anterior margin of the dilatation fits into concave posterior margin of the dilatation of the previous vertebra. The dilatations of the anterior vertebrae are short and wide, whereas those of the posterior vertebrae are narrow and long. The spinal processes of the five posterior presacrals in the specimen illustrated in Fig. 2c are broken off; consequently morphology of their dorsal parts remains unknown. V14 is the sacral vertebra. Estimated number of the caudals is at least 26 , so the total number of the vertebrae is about 40. All presacrals bore bicapitate ribs. The rib of V2 is simple, but that of V3 is widely bifurcated laterally (Fig. 2c). The rib of V4 is stout, also bifurcated laterally, but both rami are not as divergent as in V3. The specimen in Fig. $2 b_{4}$ suggests that the rami of this rib may be interconnected by a thin osseous lamina. Beginning with $\mathrm{V} 4$, the ribs bear one dorsal process, which is well discernible even at the level of V11-V12. Due to dorsoventral compression of the specimen, the ribs are twisted $90^{\circ}$ along their long axes, causing the dorsal processes in the fossil to be directed either anteriorly or posteriorly.

Among the bones of the pectoral girdle, only the scapulocoracoids are preserved (Fig. $2 a_{2}, b_{3}, 4$ ). The humerus is visible in Fig. $2 b_{2-4}$, and its dorsal crista is clearly discernible. The ulna seems to be more slender than the radius.

The carpus was ossified, and one can easily identify a robust element that is the ulnare and intermedium fused with one another, and the basal carpal for the fourth finger (Fig. 2 $b_{4}$ ).

The outlines of the pelvic girdle are visible in Fig. $2 \mathrm{a}_{3}$. The femur has a prominent trochanter. The tibia is stout, whereas the fibula is more slender. The tarsus is ossified and well preserved in the specimen illustrated in Fig. $2 a_{2,3}$. 
The proximal row consists of the tibiale, intermedium and fibulare, the medial row of the centrale and some other elements the nature of which is not clear, and the distal row of the basal tarsal for each toe. The small element at the base of the first finger might be the praehallux. The phalangeal formula is 2-3-4-4-3.

Remarks: The three specimens of Chelotriton hitherto found in Enspel provide a valuable contribution to present knowledge of the genus, because they represent by far the best preserved known articulated skeletons. Except for three articulated specimens from Rott (holotype of "Heliarchon furcillatus" von Meyer 1863 deposited in the Natural History Museum, London under the No.42731; the specimen deposited in the Geologisches-Paläontologisches Institut der Universität Bonn, coll. No. Ro-4079 and described by Hellmund and Böhme 1987; the specimen deposited in the Museum für Naturkunde in Berlin, coll. No. MB-An-45.1-2) and several articulated specimens from Öhningen (holotype of "Tylototriton primigenius" Noble 1928 deposited in the Natural History Museum, London under the No. 42742; the paratypes of "Tylototriton primigenius" from the same collections deposited under BMNH 42742 and 42761; one uncatalogued specimen in the Landessammlungen für Naturkunde Karlsruhe; two other specimens from the Teylers Museum, Haarlem and Rosengarten-Museum, Konstanz see Westphal 1978) all other material is represented by disarticulated bones, mainly by dermal bones of the skull, vertebrae and ribs.

Chelotriton is clearly a hyperossified salamandrid, which is evidenced by, among other things, heavy dermal ossification of the skull roof and ossified carpus and tarsus. The fronto-squamosal arch is a feature found only in the Salamandridae (Wake and Özeti 1969). In spite of this hyperossification, it is thought to have been a permanent water dweller because it possesses paired, bony epibranchials (Fig. 2a 2,5 ). Chelotriton is related to the Recent Tylototriton, Echinotriton and Pleurodeles, which also have bicapitate ribs with $2-3$ dorsal processes that gradually disappear towards the posterior ribs. The processes, if they are well-developed, support knob-like porous glands (Roček 1996a).

\section{Salamandridae indet.}

Material: The skull of PW1995/5804-LS (Fig. 3) is dorsally exposed, but the marginal anterior and anterolateral parts are broken off. Anterior vertebrae are disarticulated, turned upside down, and partly embedded in matrix. Beginning with V8, the vertebrae are articulated with each other but their centra are broken longitudinally. This part of the vertebral column is twisted ninety degrees thus exposing it laterally. The shoulder girdle, anterior limbs and ribs are
Fig. 2 Chelotriton paradoxus. a 1 Specimen PW1995/5810-LS embedded in epoxy resin; dorsal aspect. a Interpretative drawing of the same specimen. $\mathbf{a}_{3}$ Original position of the same individual before embedding in epoxy resin, ventral aspect. $\mathbf{a}_{4}$ Counterpart of the specimen illustrated in $\left(\mathbf{a}_{3}\right)$. $\mathbf{a}_{5}$ Skull of the specimen illustrated in $\left(\mathbf{a}_{1,2}\right)$; dorsal aspect. $\mathbf{b}_{\mathbf{1}}$ Skull of the specimen illustrated in $\left(\mathbf{b}_{\mathbf{2}, \mathbf{3}}\right)$; dorsal aspect. $\mathbf{b}_{2}$ Specimen PW1995/5809-LS embedded in epoxy resin; dorsal aspect. $\mathbf{b}_{\mathbf{3}}$ Interpretative drawing of the same specimen. $\mathbf{b}_{4}$ Original position of the same individual before embedding in epoxy resin, ventral aspect. c Specimen PW1995/5826-LS; trunk vertebrae in dorsal view

absent, whereas the distal part of one posterior, perhaps left, limb is preserved. Estimated length of the individual is $66 \mathrm{~mm}$.

Description: The bones of the skull roof are covered with irregular pits of various size and position. The suture between the frontals and parietals is distinct, located at the level of the anterior border of the postorbital vacuity. The fronto-squamosal bridge is almost as broad as the anteriorposterior length of the frontals. The surface of the anteromedial parts of the parietals is at the same level as that of the frontals, but posterolaterally it is slanting down; the border between the two parts is rounded but distinct. The posterior part of the skull is elevated (it seems that it lies above the level of the interorbital part of the skull roof) and sculptured. This elevated and sculptured part is divided in the midline, and separated from the parietals by a suture. It can be considered as medial extensions of the squamosals. The otic capsules are smooth but as suggested by the condition on the left side of the specimen where the dermal bone is broken off, there was a distinct though narrow ridge approximately parallel to the posterior margin of the otic capsule. Although the skull is embedded in sediment it seems that both capsules are not prominent posteriorly and their posterior margin is approximately rectangular to the long axis. A foramen rimmed with an elevated margin and facing posteriorly from the left otic capsule is most probably the foramen ovale. The right pterygoid protrudes anterolaterally into the orbit.

The vertebral column consists of 30 vertebrae (although the most posterior caudals are fused to form a rod-like element). The atlas is disarticulated and exposed on its anterior side. Both articular facets for the occipital condyles are rather small and widely separated. The spinal process is high and only moderately dilated at its dorsal end. The second through sixth vertebrae are exposed in ventral aspect. V4 and V9 clearly indicate that the vertebral centra are opisthocoelous. Transverse processes of V3, V6 and V7 bear two articular facets that are located along the vertical line and are connected with one another by a thin osseous lamina. The portion of the vertebral column posterior to V7 is twisted $90^{\circ}$ so that it is preserved in lateral aspect. It seems that the spinal processes were partly covered with 

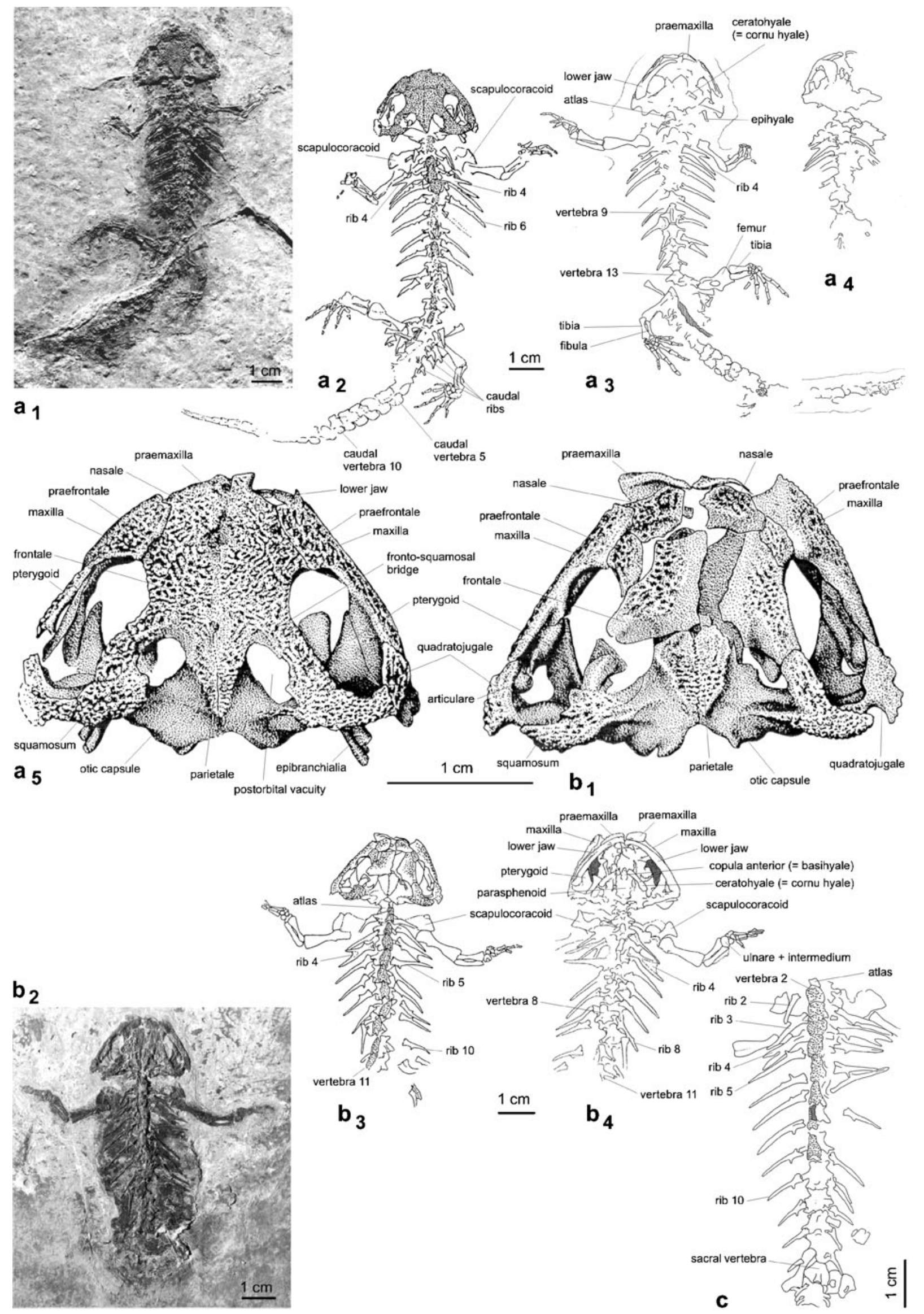

Specimen PW1995/5804-LS in dorsal view
Fig. 3 Salamandridae indet.

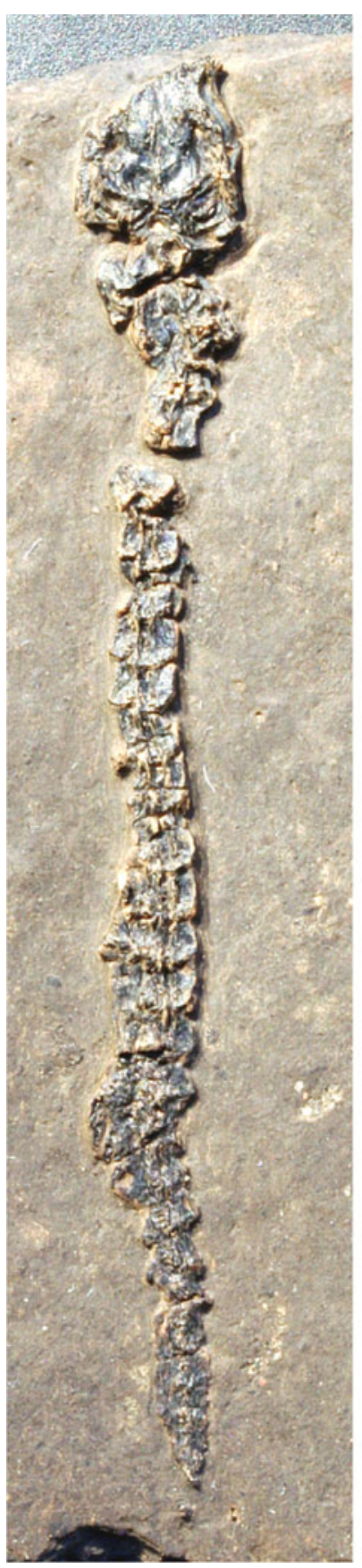

pustular sculpture on their lateral surfaces. The centra are broken along their whole length, but their outlines indicating their opisthocoelous nature is preserved. It also seems that the ventral part of the vertebrae was somewhat protruding, but the exact shape cannot be restored.

None of the ribs are preserved and except for the distal part of the posterior extremity (including articulated toes) and two fragments of the pelvic girdle, no other information about the postcranial skeleton is available.

As regards to the developmental status of the individual, the dermal roofing bones and ossified endoskeleton suggest that the specimen is neither a larva, nor an early

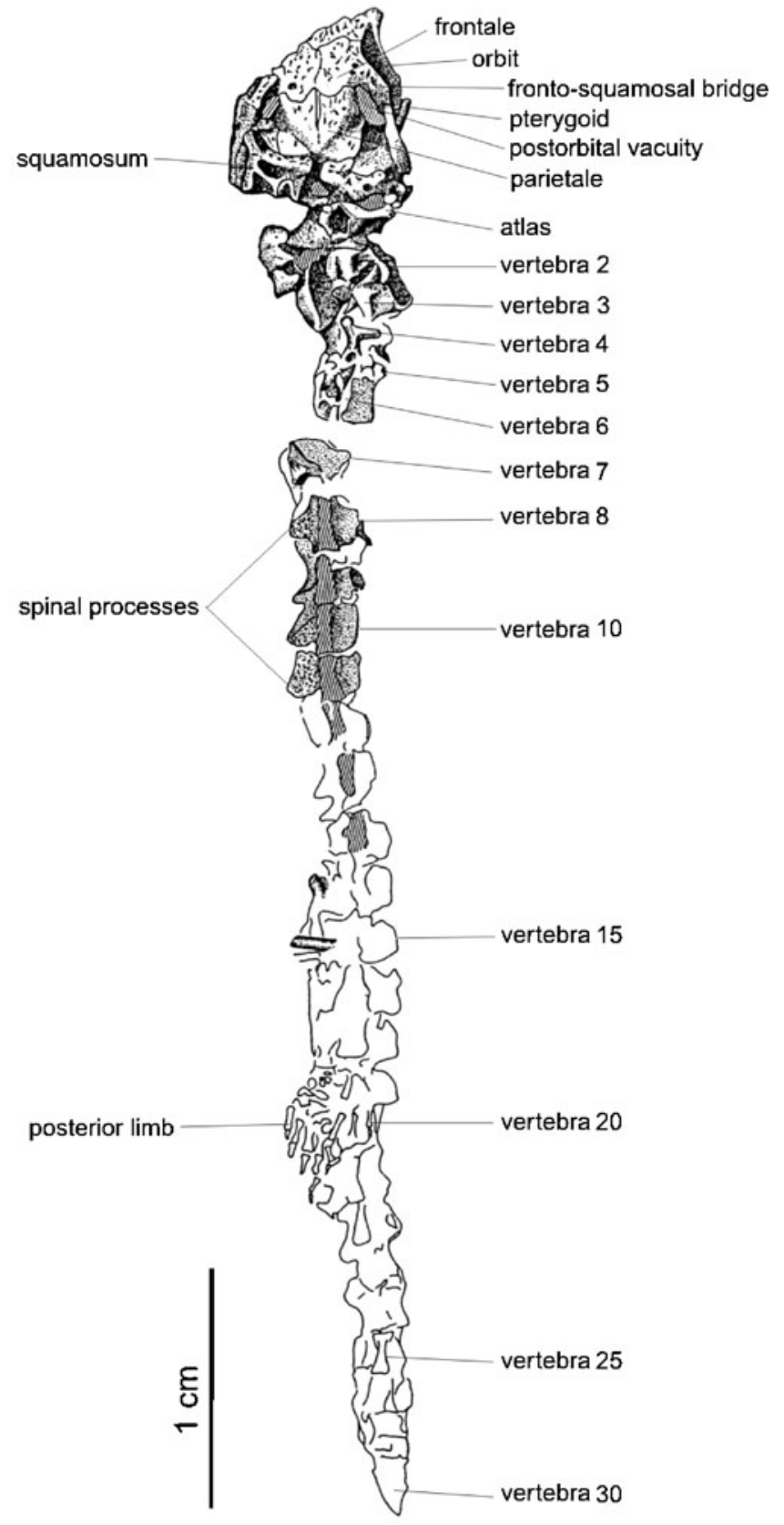

postmetamorphic individual. On the other hand, rudimentary sculpture on the skull might indicate that it is not yet fully grown and possible further development could attain closer morphological (including size) resemblance with adult Chelotriton or Palaeopleurodeles.

Remarks: The specimen was assigned to the Salamandridae on the basis of presence of the fronto-squamosal bridge and opisthocoelous vertebrae. The morphology of the skull roof may suggest relations with Pleurodeles. Judging by proportions of the vertebral column (higher number of presacrals, shorter tail), assignment to Chelotriton seems to 
be excluded. More precise taxonomic determination of the specimen is not possible because of its fragmentary preservation.

Order Anura Fischer von Waldheim, 1813

Family Palaeobatrachidae Cope, 1865

Genus Palaeobatrachus Tschudi, 1838

\section{Palaeobatrachus sp.}

Material: Two specimens were available for study, PW 2002/5000-LS, which is embedded in epoxy resin and exposed on its ventral side (Fig. 4a-f) and represents a partially preserved articulated skeleton with hindlegs broken off, and PW2008/5595-LS, which is a nearly complete skeleton exposed on its ventral side and embedded in epoxy resin (Fig. 4g, i; for palaeoenvironmental description see also Wuttke and Poschmann 2010, Fig. 2). Note that it is also documented by photographs of the dorsal side before preparation (Fig. 4h).

Description: The SVL (snout-vent-lenght, measured on the skeleton to the posterior tip of the ischia) of PW2002/5000-LS is estimated as $85 \mathrm{~mm}$; the same dimension in PW2008/5595LS is $98 \mathrm{~mm}$ ( $92 \mathrm{~mm}$ to the tip of the urostyle according to Wuttke and Poschmann 2010). The femur/tibiofibula (F/TF) ratio is 1.08 . Both individuals are adults, which is evidenced by completely ossified epiphyses of the long bones (femur, tibiofibula, humerus) and by coalesced posteriormost presacral and sacral vertebrae in PW2002/5000-LS (Fig. 4d).

The praemaxilla extends its prominent nasal process posterodorsally (Fig. 4h), and bears 5-6 tooth positions (Fig. 4g). The maxilla is dentate in its anterior portion (17 -18 tooth positions) and edentate posteriorly (Fig. $4 \mathrm{~g}$ ). It is smooth on its outer surface, pierced by small foramina, and provided with a small but well discernible frontal process (Fig. 4b, g). The frontoparietal is preserved, although fragmentary, on the dorsal surface of the skull; however, its precise outlines cannot be discerned because it is underlaid by the sphenethmoid and prootics (Fig. 4h). Part of it is also preserved in ventral aspect (Fig. 4b, g); it is obvious that it was slightly constricted near its midlength, and its ventral surface was finely striated in its anterior part. As in other palaeobatrachids, the parasphenoid is slender anteriorly and broader posteriorly; it lacks lateral alae (Fig. 4b). It is only partially preserved in both specimens but it seems that its anterior tip only moderately extends beyond the anterior margin of the sphenethmoid (Fig. 4g). The praearticular is sigmoid in shape, thin anteriorly but considerably robust posteriorly (Fig. $4 \mathrm{~b}, \mathrm{~g}$ ). Both dentaries are in situ and their thickened anterior tips (Fig. 4g) suggest the presence of ossified mentomandibulars. The pterygoids are present in PW2008/5595-LS (Fig. 4g, h), displaying both the external and internal surfaces. They are characterized by markedly beaded edges in its central part that would have enclosed the cartilaginous palatoquadrate bar in the living animal and a prominent rounded ridge on the outer surface of the anterior ramus. The otic capsules are too crushed to provide more precise information on their shape; however, the oval foramens are preserved on both sides in PW2008/5595-LS (Fig. 4g).

The vertebral centra are crushed in PW2002/5000-LS (Fig. 4e) and partly obscured by the clavicles in PW 2008/ 5595-LS (Fig. 4g), but the estimated number is 7 presacrals for both specimens. V8 is the sacral and, as suggested by the symmetrically shaped suture on its ventral surface, fused with V9 to form a synsacrum which is distinctly longer than V7 (Fig. 4g). V 8 and V9 are also sacrals in PW2002/5000-LS, which is evidenced by incompletely fused diapophyses (marked by arrow in Fig. 4d). V10 is free (well seen in Fig. 4g), connecting the sacral with the urostyle. As can be seen in ventral aspect (Fig. 4e, g), the vertebral centra are procoelous. V2-5 have stout transverse processes that apparently were terminated by cartilage in living animals. Free ribs cannot be discerned. V6 and 7 have their transverse processes moderately declined anteriorly, and those on V7 are pointed.

The clavicles are stout and their scapular process is well developed (Fig. 4e, g). The coracoids are robust, with their medial ends considerably extended (more anteriorly than posteriorly). The scapulae are short, markedly tapering towards the cavitas glenoidalis, and their anterior margins are straight. The processus glenoidalis is much shorter than the pars acromialis, and there is a distinct sinus interglenoidalis between them.

The pelvic girdle (Fig. 4c) consists of the ilia which are disarticulated and preserved in lateral aspect in both specimens, so the acetabula are partly exposed. They have no dorsal tubercle. The pubic bones are well discernible (Fig. 4c, i), the ischia are preserved in situ.

On the forelimb, the humerus has only a moderately prominent caput and bears a thin ventral crista (preserved in ventral aspect), the margin of which is turned laterally (Fig. 4g). The radioulna, although well preserved, does not provide any taxonomic information. The carpus consists of 2 elements located close to the distal end of the radioulna (radiale and ulnare, respectively), and probably also one small intermediale between them (Fig. 4f). The large oblong element on the radial side of the middle row may be interpreted as the centrale 1 . The distal row of the carpus and the metacarpals are disarticulated. The metacarpals are strongly elongated, whereas phalanges are short. The phalangeal formula is 2-2-3-3.

Remarks: The lateral processes of V6 and V7 are moderately declined anteriorly which is different from the 
Palaeobatrachus grandipes from Bechlejovice illustrated by Špinar (1972, text-fig. 18, 19A). The free V10 between the synsacrum and urostyle is considered an anomaly in Palaeobatrachus grandipes (Špinar 1972, text-fig. 18B). It is difficult to decide whether both individuals from Enspel have the same anomaly or if one free vertebra between the synsacrum and urostyle is of taxonomic importance.

\section{Palaeobatrachus cf. grandipes (Giebel, 1851)}

Material: Specimen PW1999/5007-LS (Fig. 5), which is the skull and trunk preserved in ventral aspect, without hindlimbs.

Description: Comparatively large anuran (SVL, snout-vent length, $112 \mathrm{~mm}$ ). The praemaxilla bears about 8 tooth positions. The maxilla is dentate only on its anterior portion (at least 15 tooth positions may be recognised with certainty), the posterior third of its length is edentate. The quadratojugal is absent, so the maxillary arch was incomplete. The parasphenoid extends anteriorly to the medial suture between both praemaxillae. Both pterygoids display a distinct, longitudinal rounded ridge on the ventral surface of their anterior ramus. The praearticulars are exposed in ventral aspect and bear no diagnostic features.

Only posterior five presacral vertebrae may be recognized, because the anterior part of the vertebral column is obscured. The vertebrae are clearly procoelous, and bear comparatively long, perpendicular transverse processes. The most anterior distinguishable processes are robust and slightly declined posteriorly. Free ribs cannot be recognized. The sacral diapophyses are moderately dilated and are represented by faint outlines in matrix. The urostyle has a bicondylar articulation with the sacral vertebra, and has no transverse processes. Two symmetrical and slightly posteriorly divergent elements are the medial portions of comparatively robust clavicles. The humerus is preserved in its medial aspect, which only gives a possibility to recognise its prominent ventral crista. The distal section of the front limb (not illustrated in Fig. 5) is poorly preserved, but it is obvious that fingers were long, as is typical in palaeobatrachids. The ilia are disarticulated and displaced; however, based on the right, which is preserved in lateral aspect, it is obvious that there was no dorsal tubercle on the dorsal margin of the iliac shaft, and that the acetabulum is triangular in shape, tapering anteriorly.

Remarks: Assignment to the genus Palaeobatrachus is based on the combination of the following characters: only the anterior section of the maxilla is dentate; maxillary arch is incomplete (the quadratojugal is absent); the anterior tip of the parasphenoid extends to the symphysis of the upper jaw; sacral diapophyses moderately extended (judging by a faint outlines in the matrix); urostyle lacks transverse processes.
Fig. 4 Palaeobatrachus sp. a-f Specimen PW2002/5000-LS. a Complete specimen in ventral aspect. b Ventral view of the skull. The frontal process of the maxilla marked by arrow. c Vertebral column and pelvic girdle. d Sacral vertebra in ventral view. The division between V7 and V8 marked by arrow. e Pectoral girdle in ventral view. f Carpus. g-i Specimen PW2008/5595-LS. g Skull and praesacral vertebral column in ventral view. $\mathbf{h}$ Skull in dorsal aspect (before preparation). i Complete specimen in ventral aspect

The comparatively large size of PW1999/5007-LS is reminiscent of a giant European Tertiary discoglossid Latonia (see, e.g., Roček 1994); however, the series of characters listed above point to Palaeobatrachus, rather than to Latonia.

This individual differs from the Palaeobatrachus sp. specimens described above not only by its larger size but also by the moderately larger number of tooth positions on the maxilla (although their precise count cannot be determined). Relations to $P$. grandipes are based solely on size of the specimen: large individuals of Palaeobatrachus were originally described by von Meyer (1852) as Palaeobatrachus gigas but this taxon was synonymized by Špinar (1972) with Palaeobatrachus grandipes (Giebel 1851). However, it should be emphasized that the humerus of PW1999/5007-LS from Enspel is comparatively longer than in the holotype of Palaeobatrachus gigas (see Špinar 1972, plate 87 ) $-\mathrm{SVL} / \mathrm{H}$ are 3.45 and 3.57, respectively.

Family Pelobatidae Bonaparte, 1850

Genus Pelobates Wagler, 1830

Pelobates cf. decheni Troschel, 1861

Material: Adults - PW1995/5802a (ventral aspect; Fig. 6d-g, dorsal aspect documented by photographs and drawings; Fig. 7), PW2001/5030 (dorsal aspect; Fig. 6a-c), PW2002/ 5001 (ventral aspect; Fig. 6h-k).

Tadpoles - PW1995/5774, 5842, 5878, 5880; PW1997/ 5000, 5025, 5039, 5946, 5048, 5078, 5080-5082, 5085, 50875090, 5094, 5096, 5100-5101, 5103, 5105-5106, 5108-5111, 5113, 5114, 5120-5129, 5131-5136, 5140-5143, 5147, 5148, 5164, 5173, 5180; PW1998/5001, 5026-5029, 5031, 5051, 5053, 5058; PW2001/5007, 5029; PW2002/5009-5011; PW2003/5000, 5002; PW2005/5034; PW2006/5001, 5011, 5043, 5044; PW2007/5163, 5168, 5173, 5175, 5178; 6 specimens uncatalogued. In total, 88 specimens.

Description of adults: As revealed by specimen PW2001/ 5030 in which the posterior part of the skull roof is preserved (Fig. 6a), and by specimen PW1995/5802a-LS in which the original preservation in dorsal aspect was documented by photographs and line-drawings (Fig. 7), the sculpture is of a pit-and-ridge type, rather than pustular. The medial portion of the frontoparietal is only moderately 

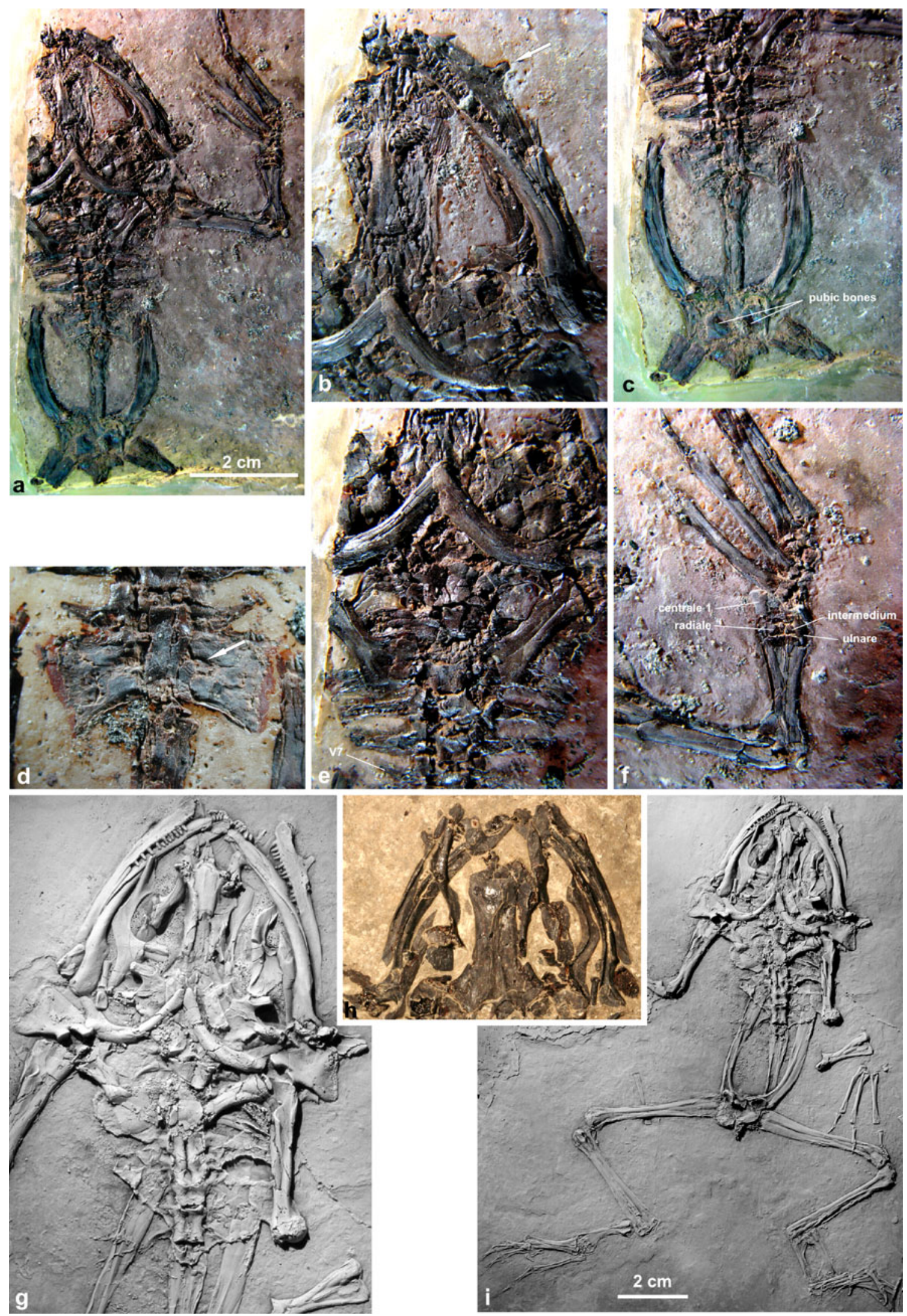


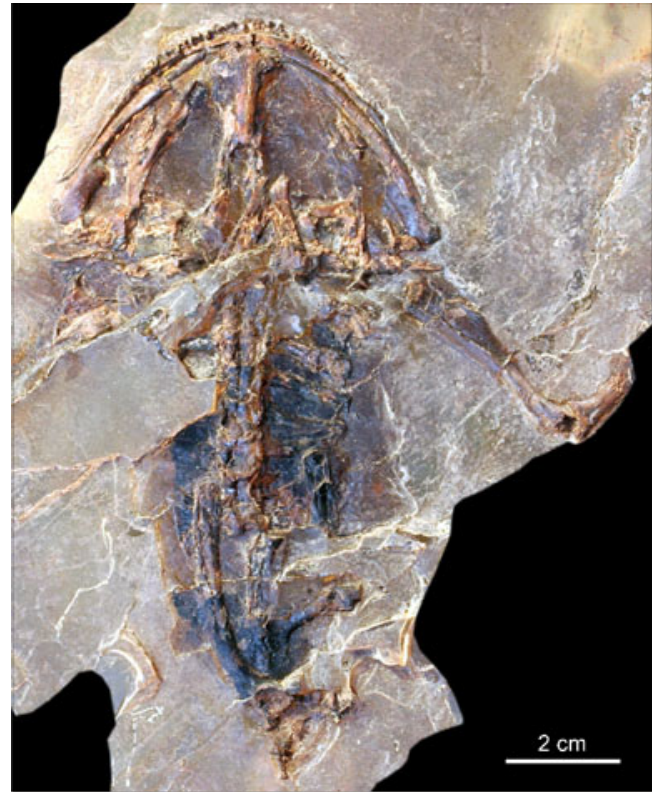

Fig. 5 Palaeobatrachus cf. grandipes. Specimen PW1999/5007-LS in ventral view

convex posteriorly and does not show any trace of a median suture. The paraoccipital processes bear a dorsal crista slanting down on their surface. Remarkably, the anterior part of the frontoparietal was still divided by a median suture and the sphenethmoid seems to have been exposed (Fig. 7), which may be evidenced by articulated circumorbital bones on the right side of the skull. Contradicting this interpretation is, however, that the anterior part of the frontoparietal fenestra of the sphenethmoid is not covered by the frontoparietal, which may suggest that the anterior portion of the frontoparietal was broken off.

The lamella alaris squamosi is large and densely sculptured. As revealed by PW1995/5802a-LS (Fig. 7c), it is terminated posteriorly by a rounded outgrowth extending below the level where the posterolateral process of the squamosum joins the lamella. Due to this, the ventro-lateral margin of the lamella is widely concave. A long and rather slender process extends from the medial margin of the lamella along the margo orbitalis to meet the corresponding process on the frontoparietal (termed the processus lateralis superior), and both form of the postorbital bridge. The lamella seems to have been separated from the posterior part of the frontoparietal by a large vacuity so that the postorbital bridge was narrow and located along the orbital margin and the otic capsule was uncovered dorsally. The frontoparietal-squamosal suture cannot be recognised in PW2001/5030-LS (Fig. 6a) and its complete obliteration cannot be excluded.

The nasals (preserved only in PW1995/5802a-LS; Fig. 7c) are surprisingly small; their medial margins are almost straight, but it is possible that they were not in
Fig. 6 Pelobates cf. decheni, adults. a-c Specimen PW2001/5030LS. a Whole specimen in dorsal view. b Pelvis and posterior part of vertebral column in dorsal view. c Sacral region in dorsal view. d-g Specimen PW1995/5802a-LS. d Whole specimen in ventral view. e Skull in ventral view. f Frontoparietal in ventral view. $\mathbf{g}$ Pectoral girdle in ventral view. $\mathbf{h}-\mathbf{k}$ Specimen PW2001/5001-LS. $\mathbf{h}$ Whole specimen in ventral view. i Sacral region in ventral view. $\mathbf{j}$ Scapula in lateral view. $\mathbf{k}$ Right carpus in ventral view

contact along their whole medial margins. Their anterolateral margin is only moderately concave and their parachoanal process is only slightly prominent. Nevertheless, the contact margin with the maxilla is long, similar to other species of Pelobates. There is also an indistinct posteromedial process of the nasal but it seems improbable that it was in contact with the frontoparietal.

The maxillary arch is complete, i.e., including the comparatively robust and sculptured quadratojugal (Figs. 6e and 7c). As is the case with extant species of Pelobates, the quadratojugal is coalesced with the quadrate and articulated with the processus posterior maxillae. As revealed by PW1995/5802a-LS (Fig. 7c), the maxilla is covered with sculpture, rather deep, with the zygomaticomaxillar and frontal processes of approximately the same size; the margo orbitalis between both is wide and only moderately concave. The processus posterior maxillae is short and not distinctly separate from the main part of the bone. The estimated number of tooth positions is 45 , and a long transverse palatine process can be seen in ventral view (Fig. 6e). The preserved dorsal aspect of the right premaxilla (Fig. 7c) suggests that this bone is not different from that in extant species of Pelobates (Roček 1981, Fig. 25).

The ventral aspect of the frontoparietal is partly exposed in PW1995/5802a-LS (Fig. 6f) but its anterior portion is obscured by the sphenethmoid, its middle portion by the exposed portion of the parasphenoid, and its posterior portion by the pectoral girdle. Although both orbital margins are preserved, it is difficult to decide whether the dorsal or ventral lateral processes are exposed (i.e., whether the orbital margins represent the margins of the tectum supraorbitale or margins of that part of the frontoparietal which is in contact with the braincase; for terminology see Roček 1981, Fig. 27b).

The parasphenoid bears a distinct rounded keel on its medial process (Fig. $6 \mathrm{f}, \mathrm{h}$ ) and both medial and lateral processes are moderately constricted near their bases which gives an impression that the lateral processes are moderately declined anteriorly (PW2002/5001-LS). Also, the pterygoid is preserved in ventral aspect in PW1995/ 5802a-LS and PW2002/5001-LS (Fig. 6e, h). Its interior ramus is straight and slender, whereas the maxillary and posterior rami taper distally from the triangular plate. The orbital margin of the pterygoid is extended by the orbital 

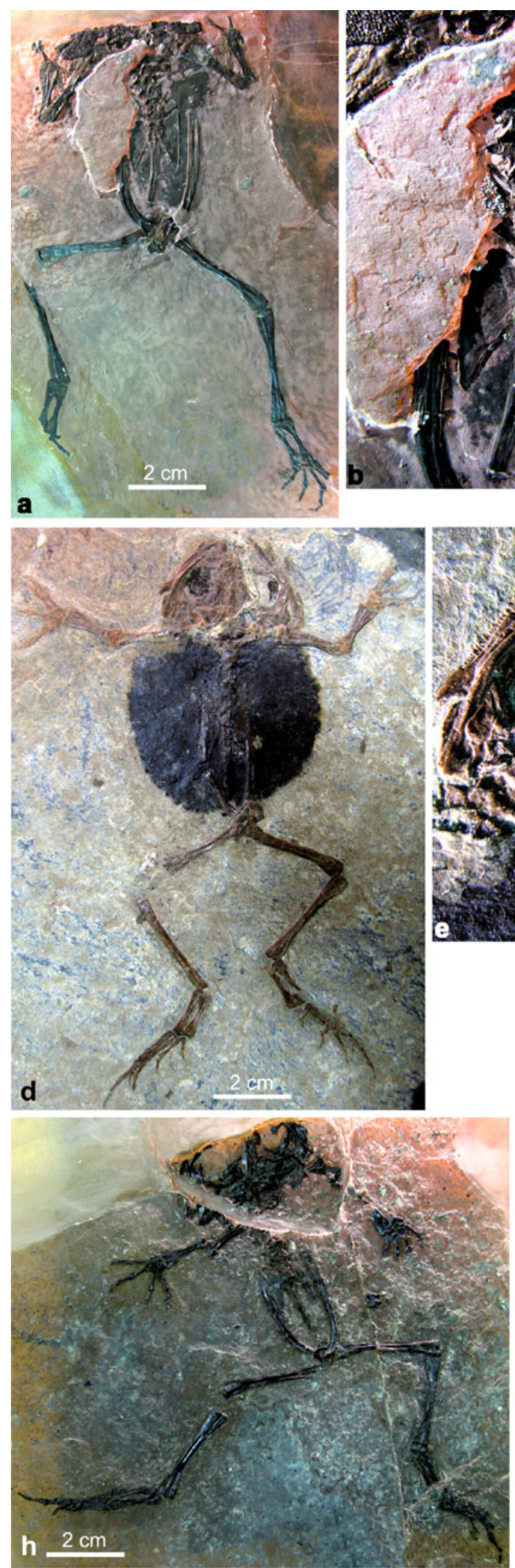
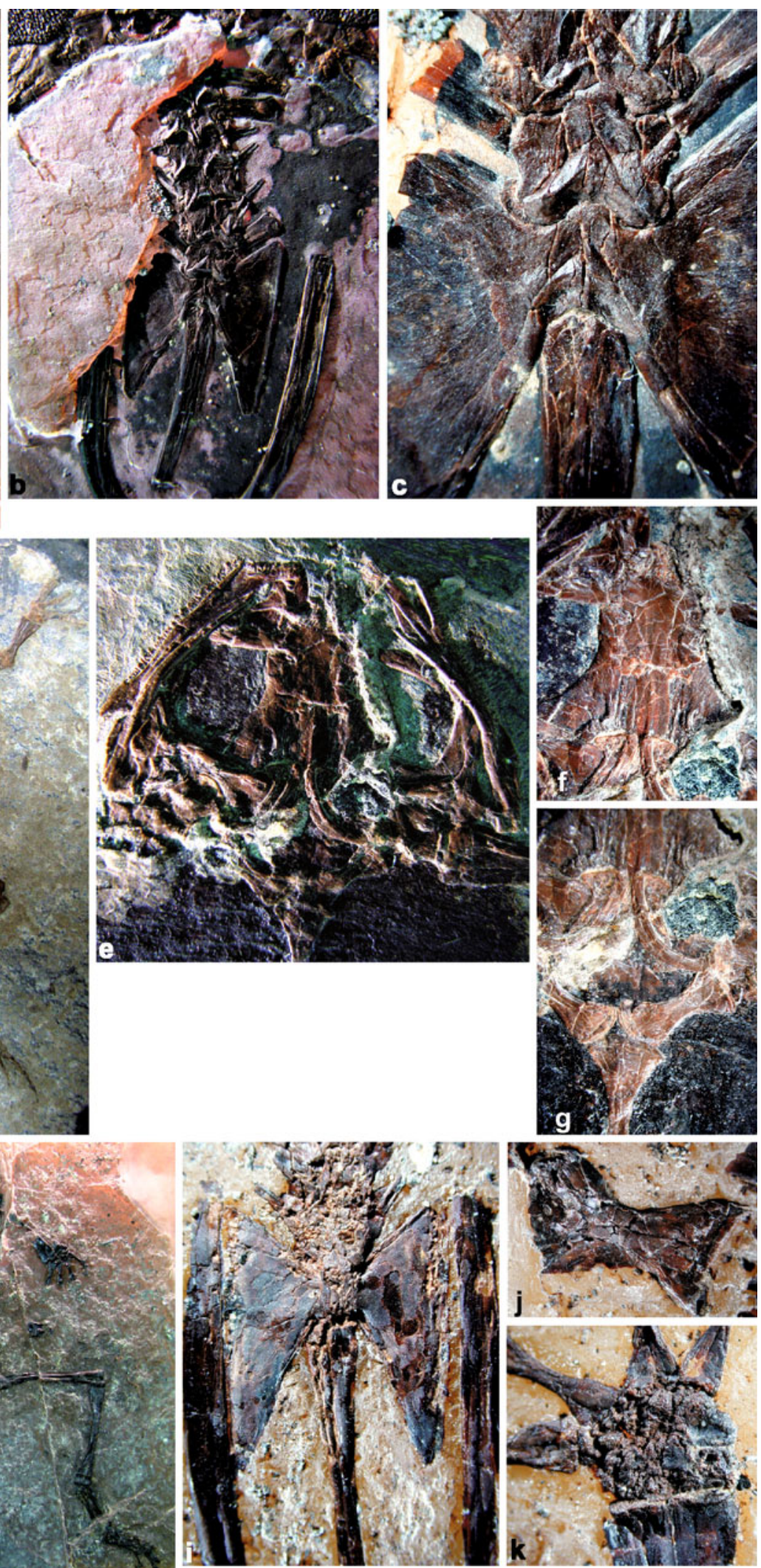
Fig. 7 Pelobates cf. decheni, adult. Specimen PW1995/ 5802a-LS in dorsal view, before this side was embedded in epoxy resin. a Whole specimen. b Interpretative line-drawing. Arrow marks the sacro-urostylar articulation. c Dorsal view of skull. Arrow marks the postorbital vacuity
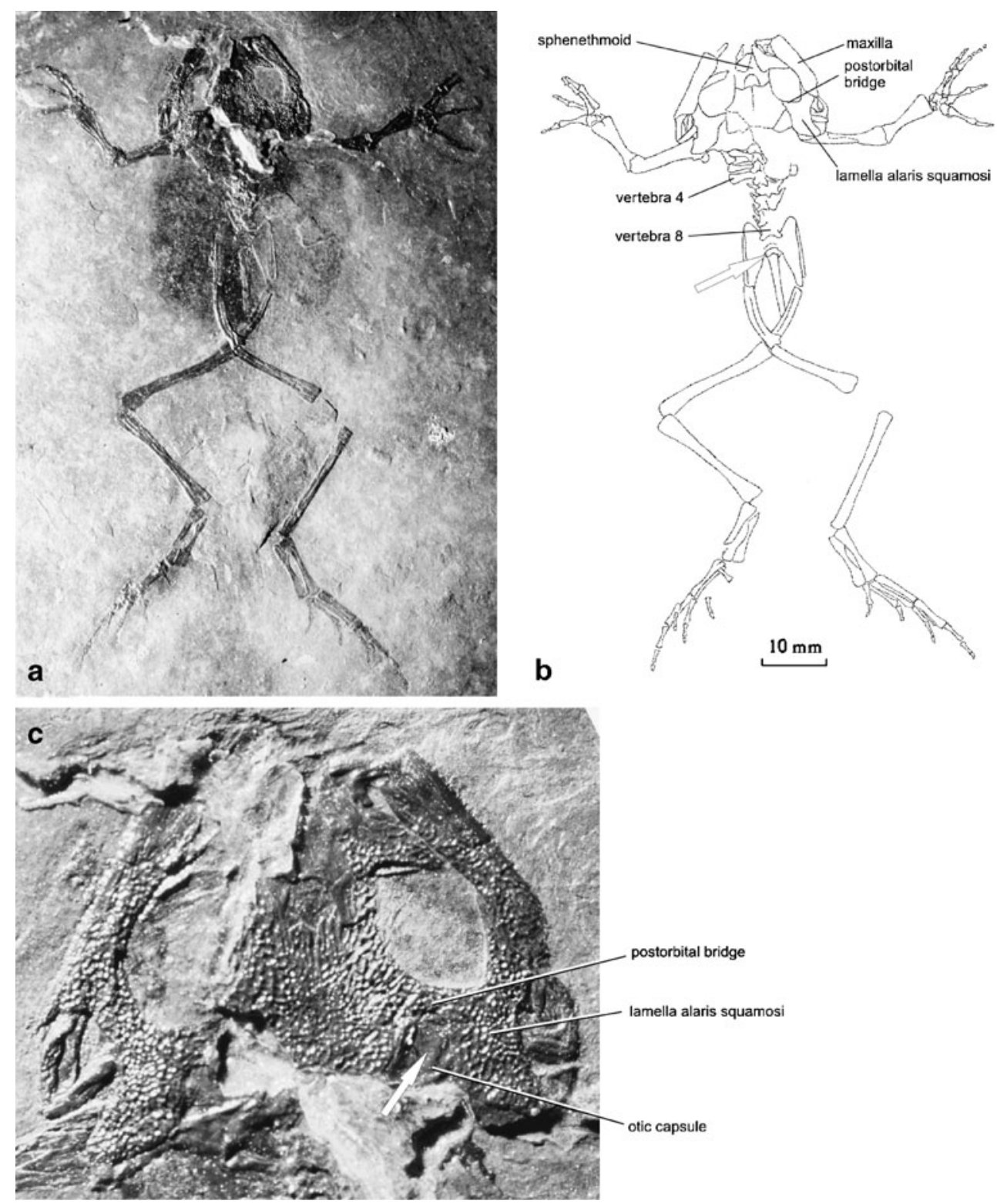

margin of the lamella alaris of the squamosum (Fig. 6e). The vomer seems to have about 12 tooth positions (Fig. 6e) but its general shape is not clear.

The total number of vertebrae is nine (including the sacral; Fig. 6b). The atlas is partly obscured by matrix and nothing can be said about its morphology. V2-V4 bear long and robust transverse processes, which are slightly dilated at their distal ends. Probably they were completed by cartilage in living animals, rather than supporting ribs, as proposed by Böhme et al. (1982). The fourth vertebra bears slender diapophyses that are half the length of those on the third vertebra (thus well visible in dorsal view), and perpendicular to the long axis of the vertebral column. The diapophyses on V5 and V6 are similar but declined anteriorly. They all display a distinct longitudinal groove on their posterodorsal surface. Rather unusual are diapophyses of the last presacral (V8) which is much more robust than the three preceding ones, attaining nearly the length of the sacral diapophyses (Fig. 6b).

The transverse processes of the sacral vertebra are dilated antero-posteriorly (more posteriorly than anteriorly), so that their posterior tips extend over the mid-length of the urostyle. They consist of the main part to which an anterior rim is added (Fig. 6c). A similar addition is discernible along the posterior margin of the sacral diapophyses; it is less clear laterally but very dictinct medially which gives an impression as if there would be two pairs of neural arches (thus two sacral vertebrae). However, there is no sign of such division in ventral aspect (Fig. 6i).

The urostyle is articulated, not firmly fused, to the sacrum (Figs. 6c, i and 7b). It is rather short: when tips of both iliac shafts are at about the same level as the most 
anterior tips of the sacral diapophyses, the urostyle does not reach the acetabular portion of the pelvis (Fig. 6a, h).

In ventral aspect the pectoral girdle consists of two archlike clavicles, which are in contact at their anterior ends (Fig. 6g), and two stout coracoids, which are in contact with one another at their medial ends. Posterior to this contact, is a triangular, ossified sternum. As all three bones are in close contact, it seems that the epicoracoid cartilages were rather restricted (if compared with contemporary Pelobates fuscus; Bayer 1884, tab. II, Fig. 5). The scapula is preserved in dorsal aspect (Fig. 6j). It is about the same width proximally and distally, being constricted by about $50 \%$ at its midlength. The suprascapula and cleithrum are not preserved. The elements of the carpus are preserved (Fig. 6k) but they are crushed and do not provide taxonomic information. The phalangeal formula is 3-3-4-4.

The iliac shafts were articulated ventrally along the lateral margin of the sacral diapophyses. The ratio femur/tibiofibula in PW2001/5030 and PW2002/5001-LS (in PW1995/5802aLS a part of the femur is obscured) is 1.0 and 1.04, respectively. The tibiale and fibulare are not coalesced in any of the three individuals. The phalangeal formula is 3-3-44. The praehallux is present (PW2002/5001-LS), but it is not modified to form a spade for digging.

In all three individuals the epiphyses of the long bones are fused to the diaphyses, which might suggest that they all were adults. However, a large part of the sphenethmoid (including the anterior part of its frontoparietal fenestra) was exposed in PW1995/5802a-LS (Fig. 7c), its frontoparietal was divided in the anterior part, and the tibiale and fibulare were not coalesced in all individuals. Although these characters usually indicate incomplete somatogenesis, in combination with complete ossification of the long bones they could be instead taken as characters of taxonomic importance.

Remarks on adults: All three individuals can be attributed to the Pelobatidae (Pelobates and Eopelobates; sensu Roček 1981; Frost et al. 2006) on the basis of the combination of the following characters: (1) the frontoparietal developing from a pair of frontoparietals and from an unpaired median element inserted between their posterior portions, which is the reason why the posterior margin of the bone is moderately convex and the median suture never reaches its posterior edge; (2) in adults, dermal roofing bones are sculptured; the sculpture develops as an integral part of the bone, not as a secondary exostosis; (3) the sacral diapophyses are strongly dilated antero-posteriorly which is associated with the sliding function of the iliosacral joint; (4) the urostyle is short, not reaching the acetabular part of the pelvis; and (5) the praehallux is present (although not forming a spade). Indirect assignment to the Pelobatidae may be based on the association with tadpoles which have their frontoparietals developing from three elements (see below; Maus and Wuttke 2004).

They can be attributed to the Oligocene-Miocene members of the genus Pelobates on the basis of (1) the broad frontoparietal-squamosal arch (this postorbital arch is absent in Eopelobates); and (2) forelimbs with four digits (sometimes vestigial fifth in Eopelobates; Špinar 1972, text-fig. 90).

They may be attributed to Pelobates decheni on the basis of the following characters: (1) the dermal roofing bones are covered by a pit-and-ridge (not pustular) sculpture; (2) the sculpture extends onto the quadratojugal; (3) the lamella alaris of the squamosum takes part in the frontoparietalsquamosal bridge; (4) the parasphenoid bears a longitudinal keel on its medial process (this, however, can be developed to some degree also in Eopelobates (Špinar 1972; Roček 1981; Špinar and Roček 1984); (5) the lateral processes of the parasphenoid moderately declined anteriorly; (6) the sacral diapophyses consist of several wing-like parts (Fig. 6c; Böhme et al. 1982, Fig. 4); and (7) the urostyle is not fused to the sacral vertebra (Fig. 6c, i; Böhme et al. 1982, Fig. 4); in Eopelobates anthracinus and E. bayeri both elements may either be fused (Roček 1995) or separate (Špinar 1972; Špinar and Roček 1984), probably depending on the age of an individual. Although in the holotype specimen of Pelobates decheni the ratio femur/tibiofibula cannot be recognised it may be used as an additional character for taxonomic assignment of Enspel individuals because in Zaphryssa, which is a junior synonym of Pelobates decheni (Böhme et al. 1982), this ratio is 1.0.

However, the specimens PW2001/5030-LS (Fig. 6a) and PW1995/5802a-LS (Fig. 7c) display a broad and deep posterior vacuity between the alar lamella of the squamosum and the frontoparietal, which makes the squamosofrontoparietal bridge rather narrow, compared with that of the holotype of Pelobates decheni which seems to lack a posterior vacuity (Böhme et al. 1982, Fig. 2). This is the reason why we can assign the pelobatids from Enspel only tentatively to $P$. decheni.

It should be emphasized that these three specimens and their tadpoles represent the earliest known record of the genus Pelobates. Absence of a spade indicates that early pelobatids still were not capable of burrowing.

Description of larvae: Pelobatid tadpoles from Enspel were described and discussed by Maus and Wuttke (2002, 2004) so we restrict our account only to the most important diagnostic characters.

The frontoparietal develops from two halves, later completed posteriorly by an unpaired element situated in the midline (e.g., Fig. 8 $\mathrm{a}_{2}$, i). This tripartite composition of the frontoparietal is the most important diagnostic character of larval Pelobates and Eopelobates. All of the 

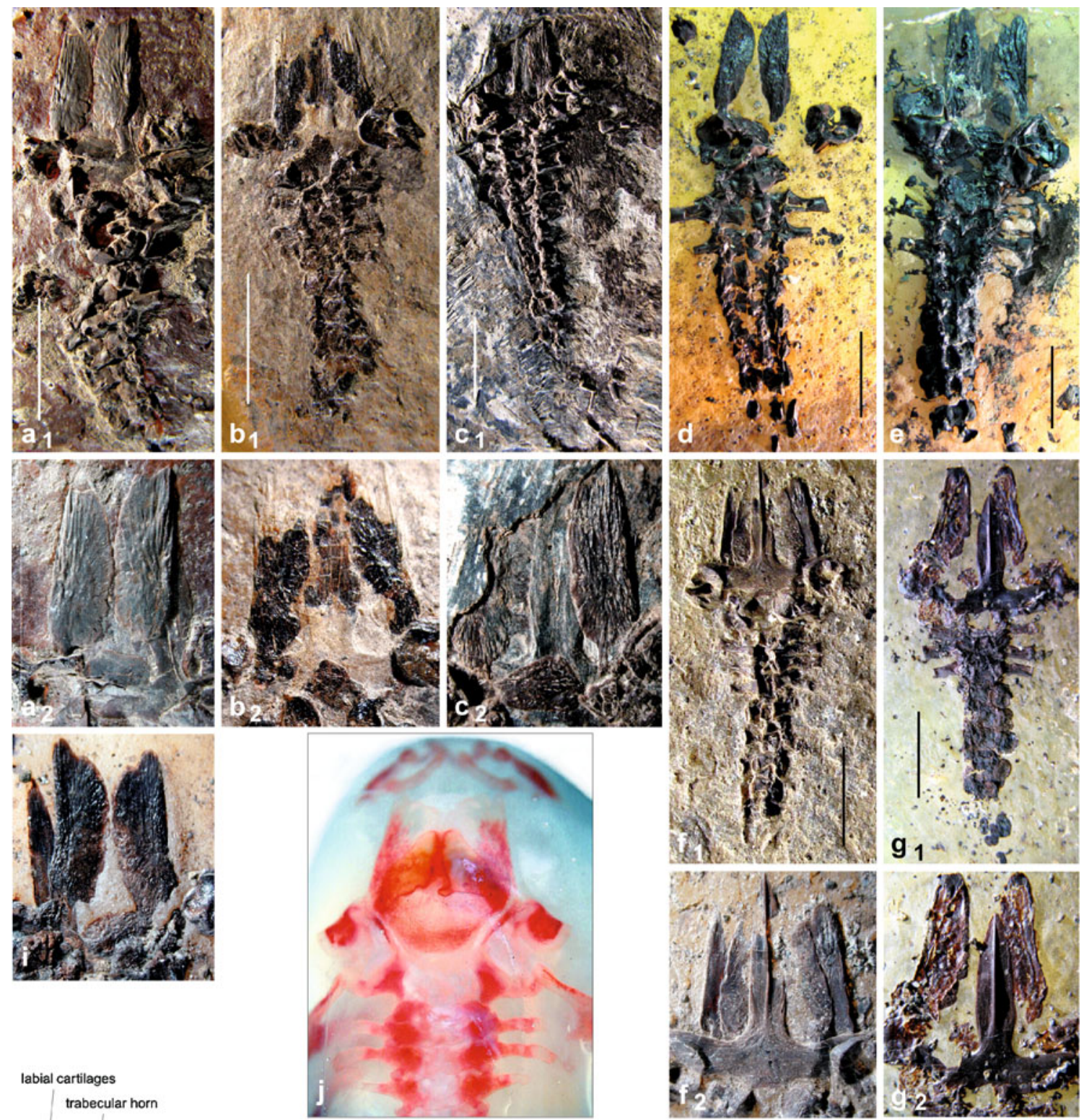

labial cartilages
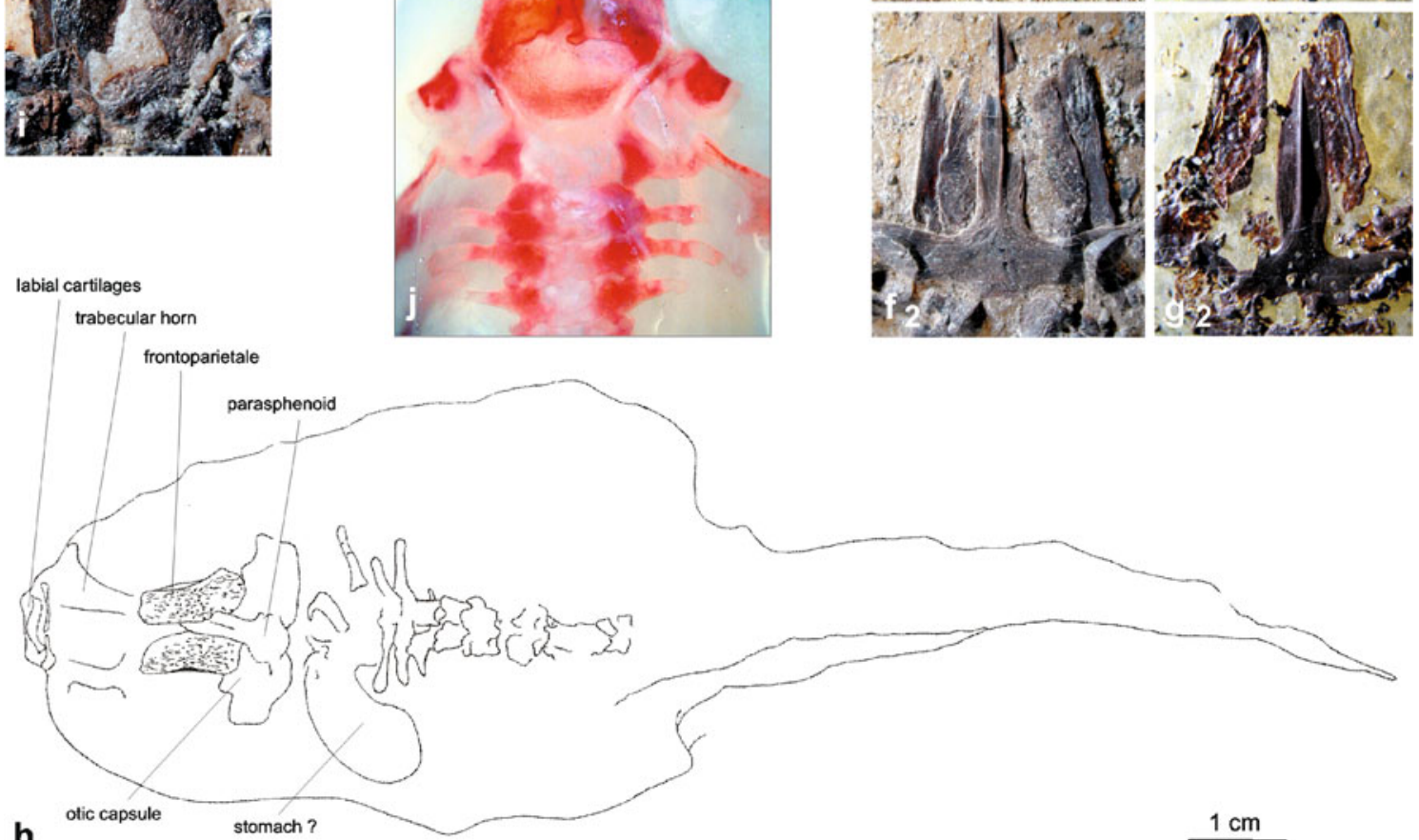
4Fig. 8 Pelobates cf. decheni, larvae. a 1 Specimen PW1997/5122-LS, dorsal aspect. $\mathbf{a}_{2}$ Detail of its frontoparietal complex. $\mathbf{b}_{1}$ Specimen PW1997/5039b-LS, dorsal aspect. $\mathbf{b}_{2}$ Detail of its frontoparietal complex. $\mathbf{c}_{\boldsymbol{1}}$ Specimen PW1997/5048-LS, dorsal aspect. $\mathbf{c}_{\mathbf{2}}$ Detail of its frontoparietal complex. d Specimen PW2002/5011-LS, dorsal aspect. e Specimen PW2003/5002-LS, dorsal aspect. $\mathbf{f}_{\mathbf{1}}$ Specimen PW1997/5121-LS, ventral aspect. $\mathbf{f}_{2}$ Detail of the skull. $\mathbf{g}_{1}$ Specimen PW1998/5051-LS, ventral aspect. $\mathbf{g}_{2}$ Detail of the skull. h Premetamorphic giant tadpole of Pelobatidae, dorsal view. Deposited in the collections of the University of Mainz, uncatalogued. i Frontoparietal complex of PW2002/5010-LS, dorsal aspect. j Recent Pelobates fuscus (DP FNSP 6568), tadpole in metamorphosis, dorsal view. Ossified parts stained by alizarin. Scale bars $1 \mathrm{~cm}$

three elements are usually well-defined, covered dorsally by sculpture, and sometimes slightly displaced, which indicates that they were well ossified. This is also supported by the well-developed frontoparietal incrassation (Fig. 8f $\mathrm{f}_{2}$; Maus and Wuttke 2004, Fig. 1), which is a thickening of the frontoparietal bones filling the dorsal fenestra of the braincase and reflecting its tecta (Jarošová and Roček 1982). As indicated by some specimens with rudiments of the hind legs (Fig. 8c; Maus and Wuttke 2004, Fig. 4), the tripartite structure of the frontoparietal persists till metamorphosis.

In ventral aspect, most significant is a distinct keel on the medial process of the parasphenoid (Fig. 8f, g), and a rounded process on the posterior margin of the bone. Whereas the latter feature occurs in all Pelobatidae, the keel is absent in all contemporary species of Pelobates, and occurs only in Pelobates decheni and Eopelobates (Špinar 1972, 204; Roček 1981; Špinar and Roček 1984).

In most individuals, there is a clear indication that the otic capsules ossified from two centres, the prootic and oticooccipital (= exoccipital) (Maus and Wuttke 2004, Fig. 1), as is the case with the contemporary Pelobates (Fig. 8j). Usually, no other parts of the skull are ossified in the premetamorphic stages and in early metamorphosis.

In premetamorphic larvae, there are eight presacral vertebrae. V2 through V4 are provided with perpendicular and stout transverse processes that were obviously completed with cartilage at their ends. In this developmental stage, the neural arches are not yet fused in the midline, and the centra are incomplete even in the most anterior vertebrae (i.e., they are pierced by the notochordal canal). Only a pair of neural arches of the first caudal vertebra (V10) can be discerned, sometimes with an unpaired element which can be interpreted as the hypochord (Fig. 8d, $g_{1}$ ).

Only a few individuals represent the metamorphosing larvae, but none of them reaching beyond Gossner stage 42 (Maus and Wuttke 2004). Although they have rudiments of hind extremities, the column still consists of 10 only partly ossified vertebrae.
Pelobatidae indet.

Description: The specimen is a large premetamorphic tadpole (Fig. 8h). The total body length is $147 \mathrm{~mm}$. It has not yet developed limbs, but the frontoparietals, parapshenoid, otic capsules and neural arches are already ossified, the latter even fused dorsally. It is deposited in the collections of the Landessammlung für Naturkunde Mainz.

The specimen preserves outlines of the body, including delicate soft parts (e.g., tail fin). Two dark parallel structures within the ethmoidal region can be tentatively interpreted as the trabecular horns. Less dubious are the transverse structures (one of them distinctly paired); these are the labial cartilages or possibly the horny beaks. Both frontoparietals are still separated from one another; their dorsal surface is covered with irregular pitand-ridge sculpture, more pronounced posteriorly than anteriorly. The lateral surface of the bones along the orbital margins is steep and separated from the dorsal horizontal surface by a distinct ridge. Between both frontoparietals, one can see the dorsal (inner) surface of the parasphenoid with a median groove. The otic capsules are fragmentary but their outlines are well defined. Two crescent-like structures posterior to the occipital part of the skull could be interpreted as displaced neural arches of the atlas. The second vertebra is lacking, but the rod-like structure situated at this level may be its transverse process. More posterior vertebrae (V3-V8) are distinct and their neural arches are fused. The sacral vertebra and anterior caudal vertebrae are still rudimentary. There is a large sac on the left side of the body in the cervical region, filled with sand grains. This is probably the stomach.

Remarks on tadpoles: Assignment of the larvae to the Pelobatidae is clearly evidenced by tripartite frontoparietal complex. A distinct median ridge on the ventral surface of the parasphenoid indicates relations to Pelobates decheni. Assignment to Eopelobates can be excluded because of absence of adult Eopelobates in this locality. Concerning the giant tadpole, it can also be assigned to the Pelobatidae, despite the unpaired median element typical for the frontoparietal complex of Pelobates and Eopelobates being absent (either lost or not yet developed). The main support for its assignment to the Pelobatidae is sculpture on both frontoparietals. The method and ossification sequence is the same in Eopelobates and Pelobates, so the tadpole could belong to either of these two genera. In contrast, the palaeobatrachid tadpoles, which may attain similar size, have a differently shaped frontoparietal. 
Family Ranidae Rafinesque, 1814

Genus Rana Linnaeus, 1758

Rana sp.

Material: Two specimens were available for study, PW2006/5019-LS (Fig. 9a-k), which is a nearly complete although fragmentary skeleton preserved in ventral view, and PW2001/5023-LS (Fig. 91-o), which is the posterior part of the vertebral column, pelvis, and the right hind-leg preserved in dorsal view.

Description: Skull is known only in ventral aspect. This is the reason why only the ventral surface of the lateral parts of the frontoparietals along their orbital margins can be onserved. The maxilla is low, lacks sculpture, is smooth on its outer surface, bearing teeth along most of its length, except for the short posterior process (Fig. 9b, d). The quadratojugal is slender and smooth and coalesced with the quadrate (Fig. 9b, g). The parasphenoid extends its medial process to the anterior margin of the sphenethmoid, both lateral processes are comparatively short and terminated by straight perpendicular or oblique margins (Fig. 9b, c). The pterygoid, preserved in ventral aspect, bears a longitudinal crista on its maxillary ramus (Fig. 9b, g). One praearticular is preserved on the left side of PW2006/5019-LS, and it is twisted $180^{\circ}$ along its long axis, so its rounded and compressed coronoid process can be seen (Fig. 9b, k).

Only three widely displaced presacral vertebrae are preserved in PW2006/5019-LS (Fig. 9e), and the two most posterior presacrals and the sacral vertebra in PW2001/ 5023-LS (Fig. 9m). The two articulated vertebrae in Fig. 9e most probably are V3 and V4, which is evidenced by robust diapophyses moderately declined posteriorly. The isolated vertebra is preserved in anteroventral aspect and, judged by its diapophyses, probably belonged to the posterior presacrals. The most posterior presacral bears comparatively robust diapophyses which taper towards their ends and are moderately declined posteriorly (Fig. 9m). The sacral vertebra also bears robust, posteriorly declined diapophyses (Fig. 9m). The urostyle is a rod-like element connected to the sacral vertebra by a movable joint, with no transverse processes (Fig. 9h, m). It is provided with a longitudinal dorsal crest extending anteriorly beyond the level of the sacro-urostylar articulation (well seen in Fig. $9 \mathrm{~m}$ where the urostyle is disarticulated and exposed in lateral aspect.

The pectoral girdle (Fig. 9f) consists of thin clavicles that are aligned perpendicular to the longitudinal body axis, and stout coracoids that are considerably dilated medially. The anterior ossified part of the sternum is nearly as long as the clavicle, the posterior part is incompletely preserved. The humerus is preserved in ventral aspect (Fig. 9a, j), but
Fig. 9 Rana sp. a-k Specimen PW2006/5019-LS. a Whole specimen in ventral view, three disarticulated vertebrae (same as in e) in upper right corner. b Skull in ventral view. $\mathbf{c}$ Parasphenoid and frontoparietal in ventral view. d Right maxilla in lateral view. e Two vertebrae articulated with one another in dorsal view, one in anteroventral view. f Pectoral girdle in ventral view. $\mathbf{g}$ Left pterygoid and quadratojugalarticular complex in ventral view. h Pelvis in ventral view. i Right tarsus in ventral view. $\mathbf{j}$ Left humerus in ventral view. $\mathbf{k}$ Right praearticular in ventral view. I-o Specimen PW2001/5023-LS. I Whole specimen in dorsal view. $\mathbf{m}$ Sacral region in dorsal view. $\mathbf{n}$ Right tarsus in dorsal view. o Right tarso-metatarsal joint in dorsal view

except for its large medial (=ulnar) epicondylus provides no other significant information.

Both ilia are displaced from their natural position in PW2001/5023-LS (Fig. 91) so that one is preserved in lateral aspect and the opposite one in medial aspect, however; they are too badly preserved to provide details of their morphology. The femur is slightly sigmoidal. The ratio between the femur and tibiofibula (F:TF) is 0.79 . The astragalus and calcaneus are not fused. No other tarsal alements are preserved.

Remarks: Both specimens clearly belong to the genus Rana (procoelous vertebrae, sacral diapophyses, and shape of the urostyle), however, further characters (e.g., morphology of the ilium) are needed for more precise determination, at least whether they belong to "brown" or "green" frogs.

\section{Discussion}

Until now, only two caudate amphibians and representatives of three anuran families had been recovered in Enspel, which represents only part of what is known about the Late Oligocene European batrachofauna (Rage and Roček 2003). This contrasts with the herpetofauna of Rott near Bonn, which is younger (MP30; Mörs 1995, 2002) than that of Enspel, and which seems to be more diversified. As regards to the caudates, besides Chelotriton paradoxus (described by Meyer in 1863 under the name Heliarchon furcillatus), Andrias scheuchzeri and Brachycormus noachicus are also known from Rott. Among anurans, Discoglossus troscheli, two currently recognised forms of Palaeobatrachus ( $P$. grandipes and $P$. diluvianus), two pelobatids (Eopelobates anthracinus, Pelobates decheni) and two ranids (Rana noeggerathi and $R$. meriani) were described from Rott. In Enspel, there are also two different forms of Palaeobatrachus (although their identity is difficult to assess), one pelobatid (Pelobates $\mathrm{cf}$. decheni), and a representative of the Ranidae. Pelobates cf. decheni is the earliest known record of the genus Pelobates. In contrast to Rott, no discoglossid has been found in Enspel until now.

Seemingly, a very common Neogene discoglossid Latonia could be expected in Enspel. The earliest definite record of an articulated skeleton of Latonia is L. vertaizoni from the 

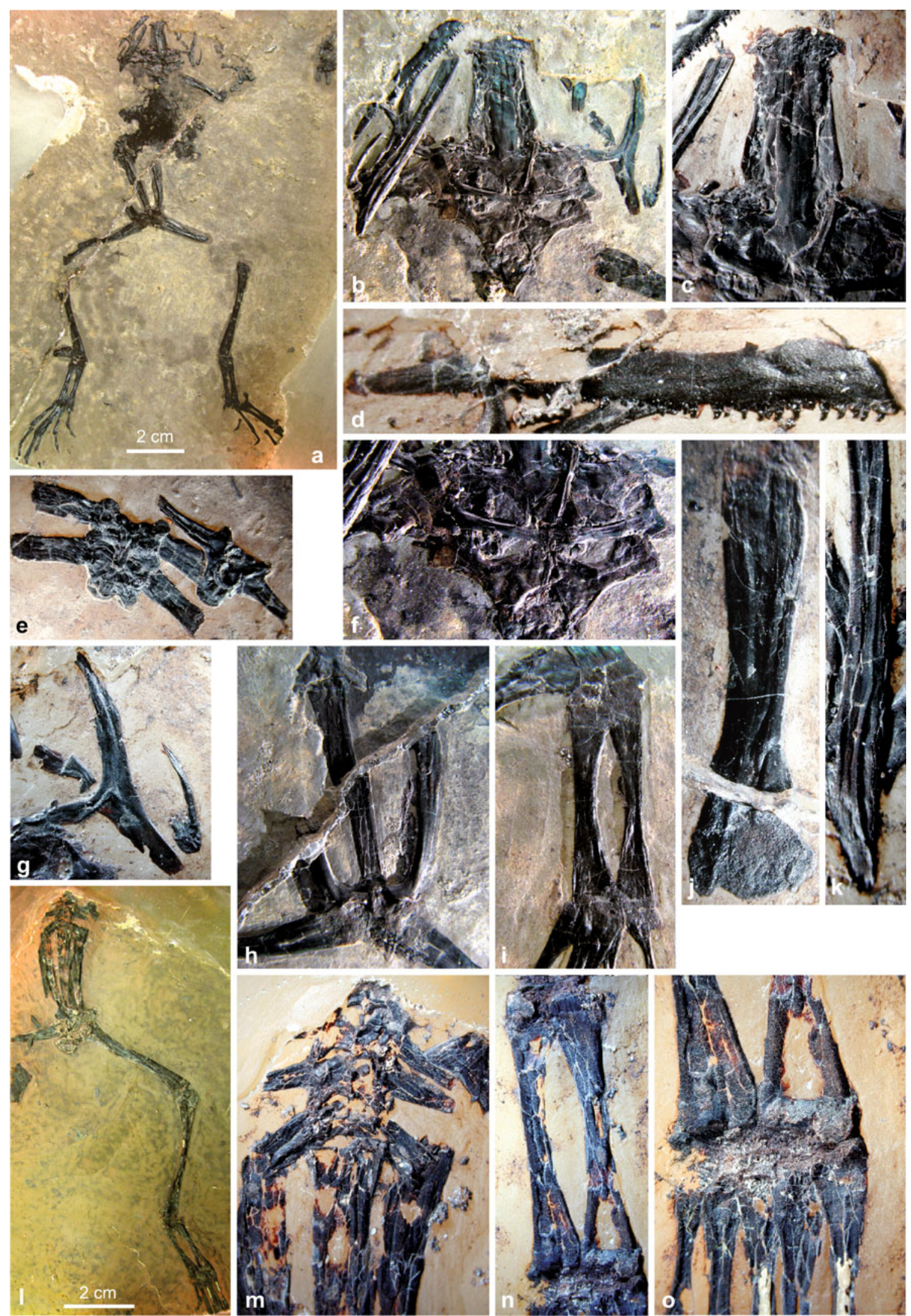
Late Oligocene of Vertaizon, France, which is different from Discoglossus troscheli (Roček 1994), so it might be seemingly expected also in Enspel. However, a very peculiar fact is that Latonia never occurs together with palaeobatrachids, even if other discoglossids are present (e.g., Opisthocoelellus hessi in Bechlejovice, Discoglossus troscheli in Rott). This suggests that ecological requirements of palaeobatrachids, which are permanent water-dwellers like pipids, and Latonia, which are thought to be land dwellers entering water only for a short period of time in the breeding season, were profoundly different. Nevertheless, other discoglossids, such as Discoglossus troscheli or Opisthocoelellus hessi might be expected also in Enspel.

Another unusual thing is that although there are a great number of pelobatid tadpoles found in Enspel, no palaeobatrachid tadpoles were found. One tends to explain this discrepancy by different niche partitioning of pelobatid and palaeobatrachid tadpoles, however, tadpoles of these anuran families were found together in Bechlejovice (Špinar 1972) and in Rott. A similar phenomenon was observed in the Miocene locality Randecker Maar (Roček et al. 2006), where only giant palaeobatrachid tadpoles but not tadpoles of normal size were recovered. One possible explanation was that the giant tadpoles appear to have lived in the more permanent (deeper) parts of that lake.

A similar problem is the absence of adult Eopelobates in Enspel (where Pelobates was present), the absence of Pelobates in Bechlejovice (where Eopelobates was abundant), and the presence of the both pelobatids in Rott.

It should be emphasized that neither Eopelobates nor Pelobates decheni were burrowers, which can be inferred from the fact that spade have never been identified in them. It is therefore impossible to simply transfer behavioural habits of contemporary representatives (even anatomically very close, such as Pelobates decheni and contemporary $P$. cultripes and $P$. varaldii) to extinct forms. It may be supposed that the burrowing in Pelobates appeared only later than in Late Oligocene.

A phenomenon not recorded in Enspel but in Rott (which might thus also be expected in Enspel) is the coexistence of two pelobatid genera (represented by Eopelobates anthracinus and Pelobates decheni) in the same locality. This is not only interesting from the point of view of phylogeny of European pelobatids (the earliest Eopelobates is recorded from the Lower Eocene, the earliest Pelobates is from Enspel; Rage and Roček 2003) but also from the point of view of coexistence of these two closely related genera at the same locality. It should be also added that Pelobates decheni has only been recorded from the Late Oligocene of Enspel and Rott, later records of disarticulated cranial elements of hyperossified Pelobates are only from the Miocene and were attributed either to Pelobates cultripes or to P. syriacus (Rage and Roček 2003).
The Enspel locality may thus be considered to represent, together with Rott and Bechlejovice, one of three important late Oligocene amphibian faunas in Europe. The most diversified of all the three is Rott which, however, might be attributed to its longer paleontological exploration. In spite of that, only three specimens of Discoglossus troscheli were recovered during a period of nearly 200 years of collecting. Similarly, only one specimen of a discoglossid Opisthocoelellus hessi (and no ranid) was recovered in Bechlejovice during extensive excavations in the period 1952-1976. It is, therefore, rather probable that the current list of amphibian taxa from Enspel will be extended by a discoglossid (other than Latonia) and perhaps also by Eopelobates with further collecting.

\section{Conclusions}

1. Until now, two salamandrid amphibians had been found in Enspel: Chelotriton paradoxus and an unidentified salamandrid which is different from Chelotriton in the number of presacral and caudal vertebrae.

2. As regards to anurans, representatives of three families were found in Enspel. The Palaeobatrachidae are represented by two distinct forms, one of them could be related to Palaeobatrachus gigas (later synonymized with $P$. grandipes), the Pelobatidae are represented by Pelobates cf. decheni (both adults and tadpoles), and the Ranidae by an unidentified ranid.

3. Pelobates cf. decheni from Enspel is the earliest record of the genus Pelobates. Absence of a spade on its praehallux indicates that it was not capable of burrowing.

4. The most abundant amphibian fossils in Enspel are tadpoles of Pelobates cf. decheni. It is difficult to explain why among a large number of pelobatid tadpoles, no palaeobatrachid tadpole was recorded.

5. Comparisons with other Late Oligocene central European localities (Rott, Bechlejovice) suggest that it is possible that the list of amphibian taxa will be extended by a discoglossid (other than Latonia) and perhaps also by Eopelobates.

Acknowledgments We would like to thank Amy Henrici, Carnegie Museum of Natural History, Pittsburgh, USA, for drawing our attention to the problem of burrowing capabilities of Pelobates decheni, as well as for her comments on an earlier draft of this paper and for linguistic corrections. Petra Schaefers and Markus Poschmann, both General Department of Cultural Heritage Rhineland Palatinate, Section Geological History of the Earth, Mainz, Germany, prepared all specimens; moreover, Markus Poschmann kindly took the pictures in Figs. 3, $4 \mathrm{~g}-\mathrm{i}$ and 5. We are grateful to Amy Henrici and J.-C. Rage for their constructive reviews. This study was supported by the Grant Agency of the Academy of Sciences of the Czech Republic No. IAA300130705 to ZR. 


\section{References}

Ahrens W (1960) Die Lagerstätten nutzbarer Steine und Erden im Westerwald. Z Dtsch Geol Ges 112:238-252

Bayer F (1884) O kostře žab z čeledi Pelobatid. Poj Král Čes spol nauk 6(12):1-24

Böhme M (2000) Die Cypriniden (Teleostei: Cyprinidae) des oberoligozänen Maares von Enspel nebst Bemerkungen zur Phylogenie und Biogeographie der Phoxininae. Palaeont $\mathrm{Z}$ 74:99-112

Böhme W, Roček Z, Špinar ZV (1982) On Pelobates decheni Troschel, 1861, and Zaphryssa eurypelis Cope, 1866 (Amphibia: Salientia: Pelobatidae) from the early Miocene of Rott near Bonn, West Germany. J Vertebr Paleontol 2:1-7

Bonaparte CL (1850) Conspectus systematicum Herpetologicae et Amphibiologicae. Editio altera reformata. Brill, Lugduni Batavorum

Cope ED (1865) Sketch of primary groups of Batrachia s. Salientia. Nat Hist Rev (N Ser) 5:97-120

Engesser B, Storch G (1999) Eomyiden (Mammalia, Rodentia) aus dem Oberoligozän von Enspel im Westerwald (Westdeutschland). Eclogae Geol Helv 92:483-493

Felder M, Weidenfeller M, Wuttke M (1998) Lithologische Beschreibung einer Forschungsbohrung im Zentrum des oberoligozänen, vulkanolakustrinen Beckens von Enspel/Westerwald (Rheinland-Pfalz; Bundesrepublik Deutschland). Mainzer Geowiss Mitt 27:101-136

Fischer von Waldheim G (1813) Zoognosia tabulis synopticis illustrata, in usum prælectionum Academiæ Imperialis MedicoChirurgicæ Mosquensis edita. 3rd edn. Vol. 1. Nicolai Sergeidis Vsevolozsky, Moscow

Frey E, Monninger S (2010) Lost in action - the isolated crocodilian teeth from Enspel and their interpretive value. Palaeobio Palaeoenv 90:65-81

Frost DR, Grant T, Faivovich J, Bain RH, HaasA HCFB, De Sá RO, Channing A, Wilkinson M, Donnelan SC, Raxworthy CJ, Campbell JA, Blotto BL, Moler P, Drewes RC, Nussbaum RA, Lynch JD, Green DM, Wheeler WC (2006) The amphibian tree of life. Bull Am Mus Nat Hist 297:1-370

Giebel CG (1851) Über eine neue Art von Palaeophrynos Tsch. aus dem Braunkohlengebilde des Siebengebirges. Jahresber Naturwiss Ver Halle 3:44-48

Goldfuss GA (1820) Handbuch der Zoologie. Zweite Abtheilung. Schrag, Nürnberg

Hellmund M, Böhme W (1987) Zweiter Fund eines vollständiges Exemplares von Chelotriton paradoxus Pomel, 1853 aus dem Oberoligozän von Rott bei Bonn. Salamandra 23:142152

Hessisches Landesamt für Bodenforschung (1989) Geologische Übersichtskarte von Hessen 1:300 000, 4th Edition.

Ivany LC, Patterson WP, Lohmann KC (2000) Cooler winters as a possible cause of mass extinctions at the Eocene/Oligocene boundary. Nature 407:887-890

Jarošová J, Roček Z (1982) The incrassatio frontoparietalis in frogs, its origin and phylogenetic significance. Amphibia-Reptilia 3:111-124

Kromer H (1980) Tertiary Clays in the Westerwald Area. Geol Jahrb D39:69-84

Landesamt für Geologie und Bergbau Rheinland-Pfalz (2003) Geologische Übersichtskarte von Rheinland-Pfalz 1:300 000

Linnaeus C (1758) Systema Naturae, Ed. X. Impensis Direct. Laurentii Salvii, Holmiae

Maus M, Wuttke M (2002) Comparative anatomical and taphonomical examination of the larvae of Pelobates decheni Troschel 1861 and Eopelobates anthracinus Parker 1929 (Anura: Pelobatidae) found at the Upper Oligocene sites at Enspel (Westerwald/Germany) and Rott (Siebengebirge/Germany). Cour Forsch-Inst Senckenberg 237:129-138
Maus M, Wuttke M (2004) The ontogenetic development of Pelobates cf. decheni tadpoles from the Upper Oligocene of Enspel (Westerwald/Germany). Neues Jahrb Geol Palaeontol Abh 232:215-230

Mayr G (2007) A small representative of the Phalacrocoracoidea (cormorants and anhingas) from the late Oligocene of Germany. Condor 109:930-943

Mayr G, Poschmann M, Wuttke M (2006) A nearly complete skeleton of the fossil galliform bird Palaeortyx from the late Oligocene of Germany. Acta Ornithol 41:129-135

Mertz DF, Renne PR, Wuttke M, Mödden C (2007) A numerically calibrated reference level (MP 28) for the terrestrial mammalbased biozonation of the European Upper Oligocene. Int J Earth Sci (Geol Rundsch) 96(2):353-361

Meyer W, Stets J (2000) Das Rheintal zwischen Bingen und Bonn. Sammlung geologischer Führer 89. Borntraeger, Berlin

Mörs T (1995) Die Sedimentationsgeschichte der Fossillagerstätte Rott und ihre Alterseinstufung anhand neuer Säugetierfunde (Oberoligozän, Rheinland). Cour Forsch-Inst Senckenberg 187:5-101

Mörs T (2002) Biostratigraphy and paleoecology of continental Tertiary vertebrate faunas in the Lower Rhine Embayment (NW-Germany). Neth J Geosci 81:177-183

Mörs T, Kalthoff D (2010) A new species of Amphilagus (Mammalia: Lagomorpha) from the Late Oligocene lake deposits of Enspel (Westerwald, Germany). Palaeobio Palaeoenv 90:83-98

Mörs T, von Koenigswald W (2000) Potamotherium valletoni (Carnivora, Mammalia) aus dem Oberoligozän von Enspel im Westerwald. Senck leth 80:257-273

Mosbrugger V, Utescher T, Dilcher DL (2005) Cenozoic continental climatic evolution of Central Europe. Proc Natl Acad Sci USA 102:14964-14969

Noble GK (1928) Two new fossil amphibia of zoögeographic importance from the Miocene of Europe. Am Mus Novit 303:1-13

Pomel M (1853) Catalogue méthodique et descriptif des vertébrés fossiles découverts dans le bassin hydrographique supérieur de la Loire, et surtout dans la valée de son affluent principal, l'Allier. Baillère, Paris

Poschmann M, Schindler T, Uhl D (2010) Fossil-Lagerstätte Enspel a short review of current knowledge, the fossil association, and a bibliography. Palaeobio Palaeoenv 90:3-20

Prothero DR (1994) The late Eocene-Oligocene extinctions. Annu Rev Earth Planet Sci 22:145-165

Rafinesque CS (1814) Fine del prodromo d'erpetologia siciliana. Specchio delle Scienze, o, Giornale Enciclopedico di Sicilia 2:102-104

Rage J-C, Roček Z (2003) Evolution of anuran assemblages in the Tertiary and Quaternary of Europe, in the context of palaeoclimate and palaeogeography. Amphibia-Reptilia 24:133-167

Rage JC, Roček Z (2007) A new species of Thaumastosaurus (Amphibia: Anura) from the Eocene of Europe. J Vertebr Paleontol 27:329-336

Roček Z (1981) Cranial anatomy of frogs of the family Pelobatidae Stannius, 1856, with outlines of their phylogeny and systematics. Acta Univ Carol Biol 1980:1-164

Roček Z (1994) Taxonomy and distribution of Tertiary discoglossids (Anura) of the genus Latonia v. Meyer, 1843. Geobios 27:717751

Roček Z (1995) A new specimen of Eopelobates (Anura: Pelobatidae) from the Tertiary near Bonn (Germany) and the problem of $E$. anthracinus- $E$. bayeri relations. Paläontol Z 69:283-287

Roček Z (1996a) The salamander Brachycormus noachicus from the Oligocene of Europe, and the role of neoteny in the evolution of salamanders. Palaeontology 39:477-495

Roček Z (1996b) Skull of the neotenic salamandrid amphibian Triturus alpestris and abbreviated development in the Tertiary Salamandridae. J Morphol 230:187-197 
Roček Z, Lamaud P (1995) Further data on Thaumastosaurus bottii De Stefano, 1903, an anuran (Leptodactylidae) from the Eocene of Europe. J Vertebr Paleontol 15:506-515

Roček Z, Böttcher R, Wassersug R (2006) Gigantism in tadpoles of the Neogene frog Palaeobatrachus. Paleobiology 32:666-675

Scopoli I (1777) Introductio ad historiam naturalem sistens genera lepidum, plantarum, et animalium. Gerle, Prague

Schindler T, Wuttke M (2010) Geology and limnology of the Enspel Formation (Chattian, Oligocene; Westerwald, Germany). Palaeobio Palaeoenv 90:21-27

Špinar ZV (1972) Tertiary frogs from Central Europe. Academia, Prague

Špinar ZV, Roček Z (1984) The discovery of the impression of the ventral side of Eopelobates anthracinus Parker, 1929 holotype. Amphibia-Reptilia 5:87-95

Storch G, Engesser B, Wuttke M (1996) Oldest fossil record of gliding in rodents. Nature 379:439-441

Toporski JKW, Steele A, Westall F, Avci R, Martill DM, McKay DS (2002) Morphological and spectral investigation of exceptionally well-preserved bacterial biofilms from the Oligocene Enspel formation, Germany. Geochim Cosmochim Acta 66:1773-1779

Troschel FH (1861) Uebersicht aller bisher aus der Braunkohle des Siebengebirges beschriebenen fossilen Tiere. Sitzungsber Niederrhein Ges Bonn 1861:55-56

Uhl D, Herrmann M (2010) Palaeoclimate estimates for the Late Oligocene taphoflora of Enspel (Westerwald, West Germany) based on palaeobotanical proxies. Palaeobio Palaeoenv 90:3947

Utesher T, Mosbrugger V, Ashraf AR (2000) Terrestrial climate evolution in northwest Germany over the last 25 million years. Palaios 15:430-449

von Koenigswald W, Martin T, Mörs T, Pfretzschner HU (1992) Die oberoligozäne Wirbeltierfauna von Rott bei Hennef am
Siebengebirge. Synonymien und Literatur 1828-1991. Decheniana 145:312-340

von Meyer H (1852) Mittheilungen an Professor Bronn gerichtet. Neues Jb Miner Geogn Geol Petrefact 1852:465-468

von Meyer H (1863) Heliarchon furcillatus, ein Batrachier aus der Braunkohle von Rott im Siebengebirge. Palaeontogr Abt A 10:292-298

von Tschudi JJ (1838) Classification der Batrachier mit Berücksichtigung der fossilen Thiere dieser Abtheilung der Reptilien. Petitpierre, Neuchâtel

Wagler J (1830) Natürliches System der Amphibien, mit vorangehender Classification der Säugthiere und Vögel. Cotta, München

Wake DB, Özeti N (1969) Evolutionary relationships in the family Salamandridae. Copeia 1969:124-137

Westphal F (1958) Die Tertären und rezenten Eurasiatischen Riesensalamander (Genus Andrias, Urodela, Amphibia). Palaeontogr Abt A 110:20-92

Westphal F (1978) Tylototriton (Amphibia, Urodela) aus dem Obermiozän von Öhningen. Neues Jahrb Geol Paläontol Mh 1978:491-501

Wolfe JA (1978) A paleobotanical Interpretation of Tertiary climates in the Northern Hemisphere. Am Sci 66:694-703

Wolfe JA (1980) Tertiary climates and floristic relationships at high latitudes in the Northern Hemisphere. Palaeogeogr Palaeoclimatol Palaeoecol 30:313-323

Wuttke M, Poschmann M (2010) First finding of fish in the diet of a water-dwelling extinct frog Palaeobatrachus from the Upper Oligocene Fossil-Lagerstätte Enspel (Westerwald Mountains, Western Germany). Palaeobio Palaeoenv 90:59-64

Zanazzi A, Kohn MJ, MacFadden BJ, Terry DO (2007) Large temperature drop across the Eocene-Oligocene transition in central North America. Nature 445:639-642 